\title{
THE CONTROL OF LAND USE FOR DEVELOP URBAN EFFICIENCY IN EGYPT \\ "THE CASE STUDY OF THE GREATER CAIRO REGION"
}

\section{Mohammed Hassan Atwa}

Associate Professor, Department of Architecture \& Urban Planning, Faculty of Engineering, Suez Canal University, Egypt

(Received November 24, 2007 Accepted May 19, 2008)

The land of which it is based projects sites important to be available amounts required by the operations of different types of construction land is a key to human development and construction, thus, the land is one important resources important work of the progress that needs to be an effective administration for the development of architectural. It must be rehabilitation and study of controlling the land uses in best the light of current development within the various regions of the Territory and whether these existing uses "land space - uses different workshops - stores - airport - stadium - factories - graves - slums".

The research tries to monitor the most important experiences of local and global and Arab successful in this matter and ends after a series of findings of the study theoretical and applied, which would see the formation of comprehensive and integrated manner enables us to develop the urban efficiency in Egypt.

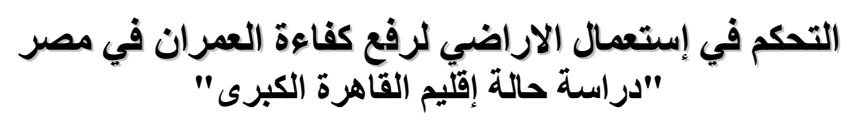

\section{ملخص البحث:}

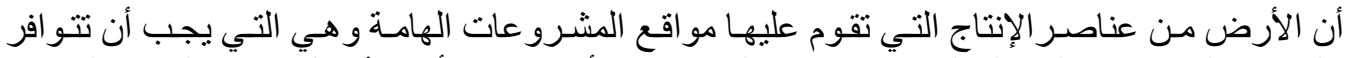

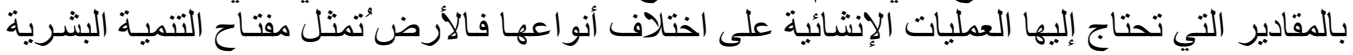

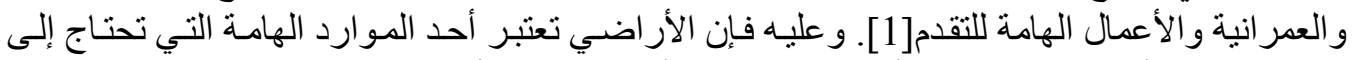

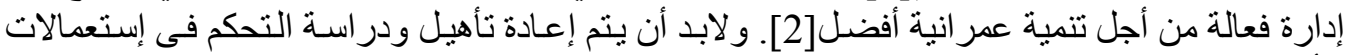

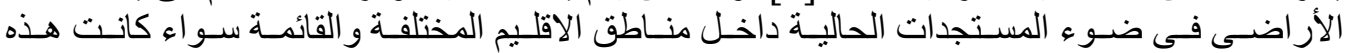

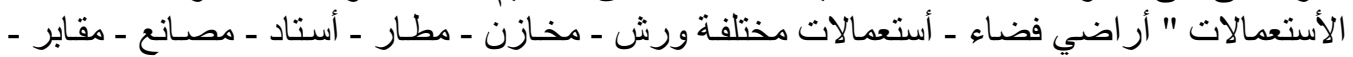

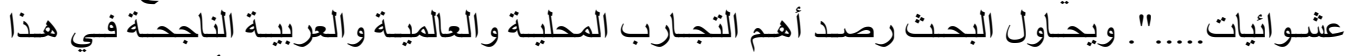

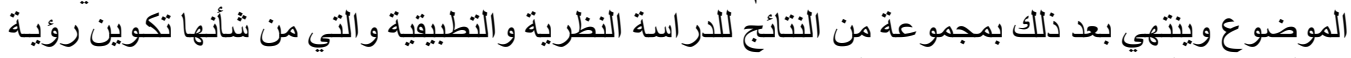

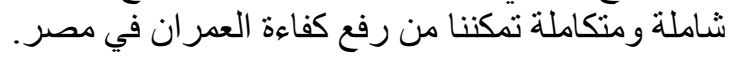

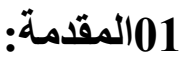
101

أن مصر من الدول النامية التي تعاني من سوء توزيع استعمالات الأراضي في مدنها مما أنعكس على الته

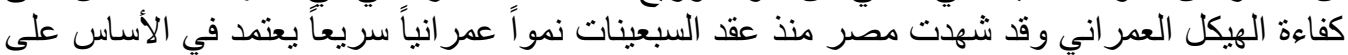


سياسات عمر انية قطاعية (Sector Policies) أدت إلى زيادة انتشار ظاهرة العشو ائيات الغير مخططة

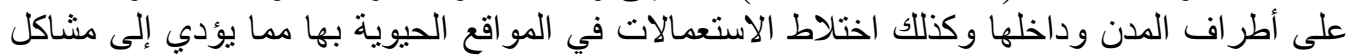
عمر انية واجتماعية واقتصادية كبيرة تؤثر على كفاءة الخطط القومية الخية الخاصة بإعادة التتمية.

201

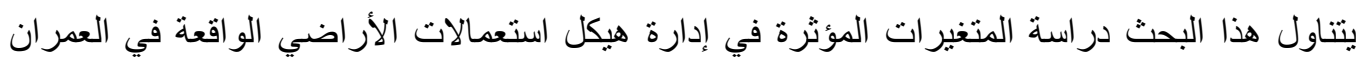

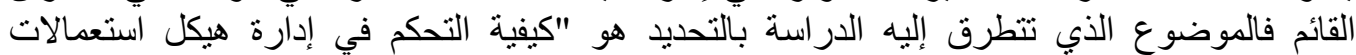

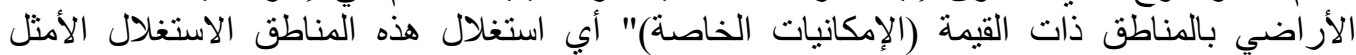

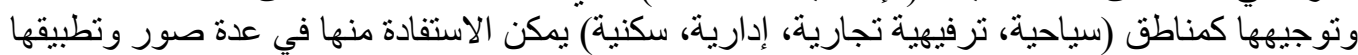

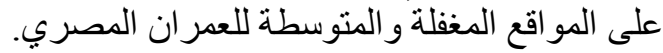

\section{1 فرضية ومنهجية البحث:}

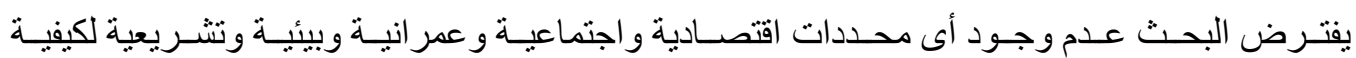

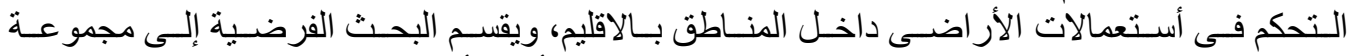

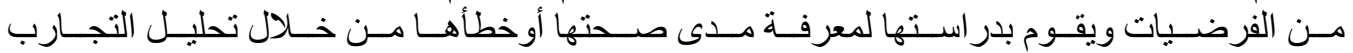

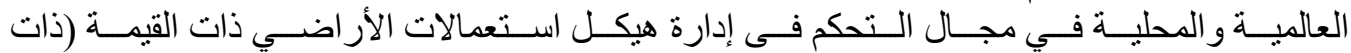

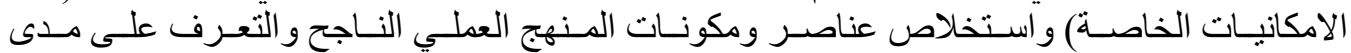

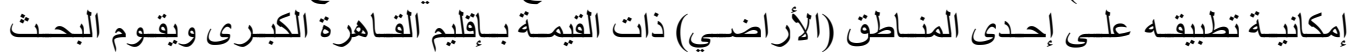

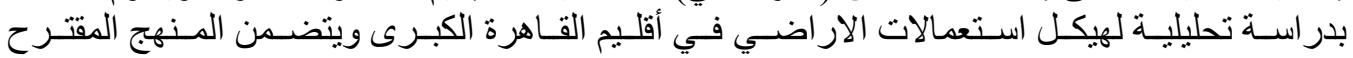
للبحث مدخلين هامين هما:

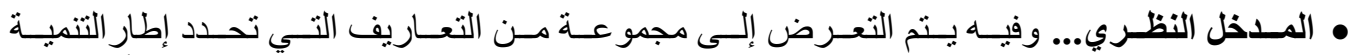

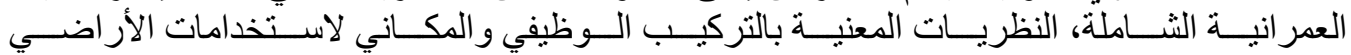

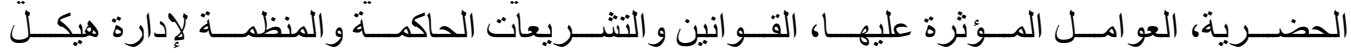

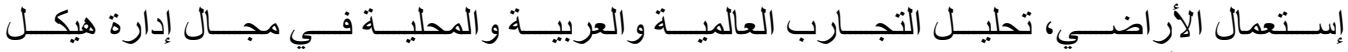
استعمالات الأر اضي ذات القات القيمة.

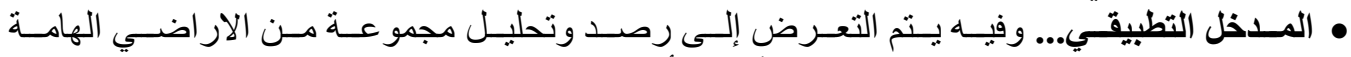

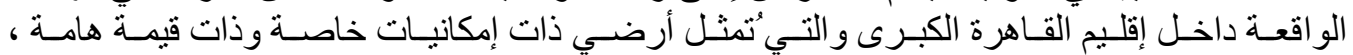

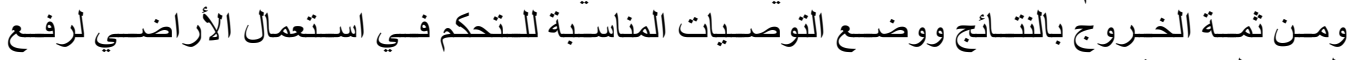
الكفاءة العمر انية بها.

\section{2}

\section{2 التعاريف التي تحدد إطار التنمية العمرانية الثاملة:

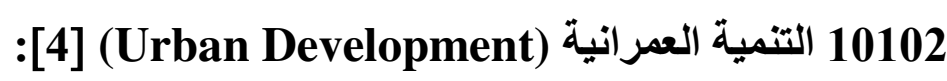

هي تللك العمليات والأنشطة التي يقوم بها تنظيم حكومي وتستهدف التخطيط بكافة أنو اعهد وكافة مستوياته

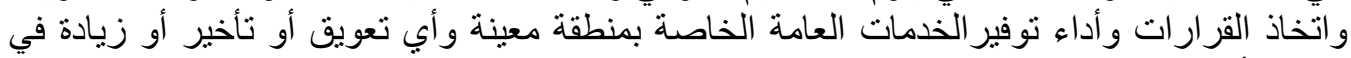

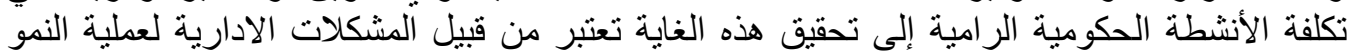

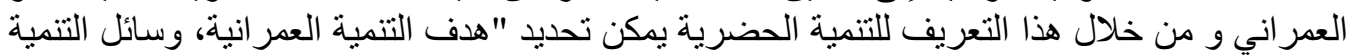
العمر انية، سمات التتمية العمر انية". 
20102

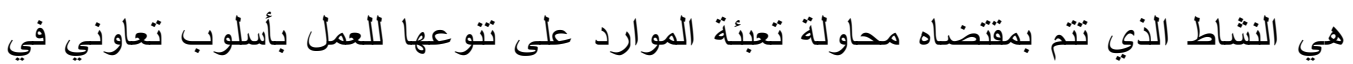

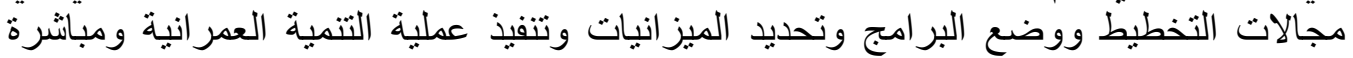
أعمال التثغيل و الصيانة وذلك بفرض تحقيق الأهداف التتموية للمدينة.

\section{2 النمو العمراني (Urban Growth)}

هو حالة امتداد المدينة وتداخلها في ضواحئها الحيها الريفية في الأغلب الأعم وتركيب المدينة (بنية المدينة

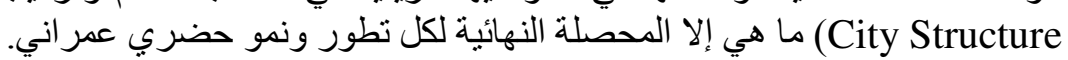

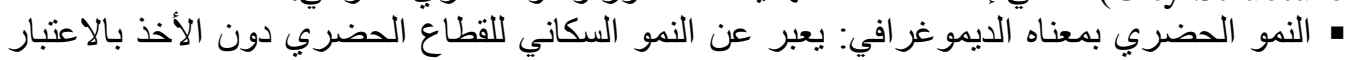
النمو السكاني للقطاع الريفي و النمو العام للسكان. • النمو الحضري بمعناه العمر اني: فيعني التوسع و الامتداد العمر اني (Physical Growth) للقطاعات التصات الحضرية بصفة عامة و المدن بصفئة خاصئة.

\section{2}

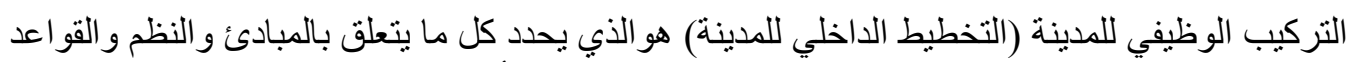

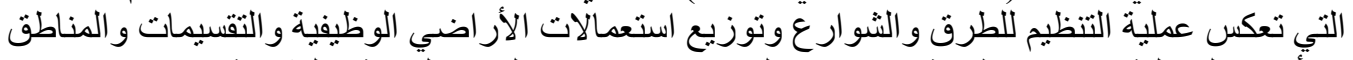

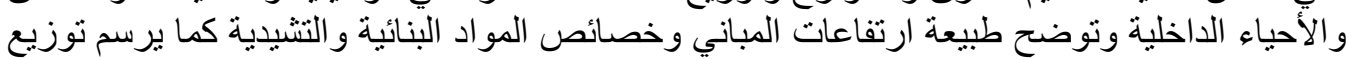

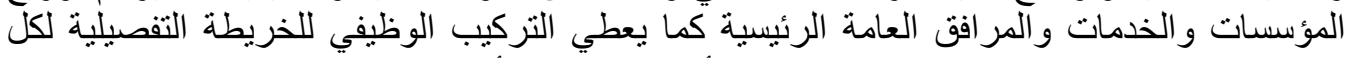

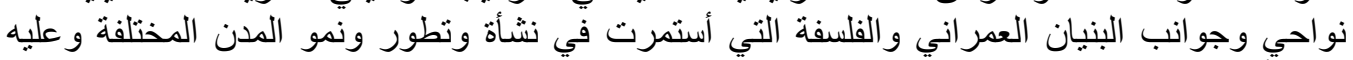

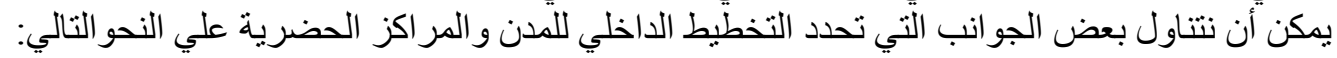

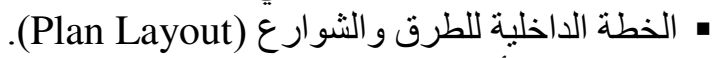
• استعمالات الأر اضي الوظيفية (Functional Land Uses). • الأحياء و النطاقات الّاخلية والأسلوب المعماري للمباني (Internal Zones and Architectural).

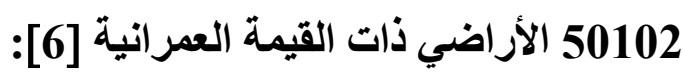

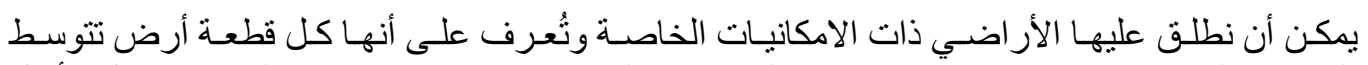

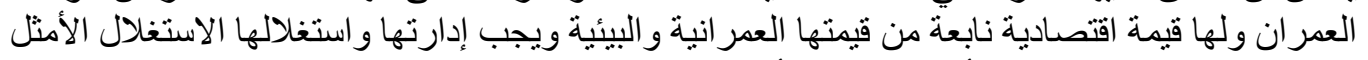

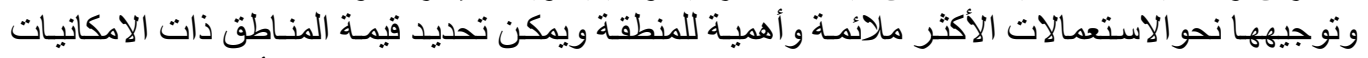

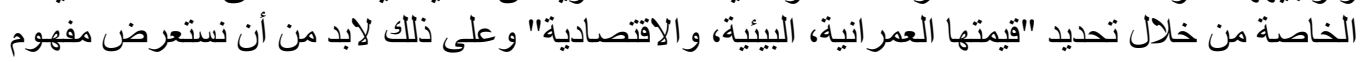
القيمة ومعاير ها.

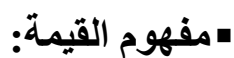

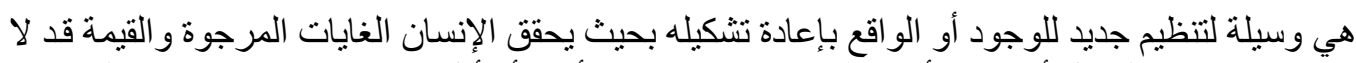

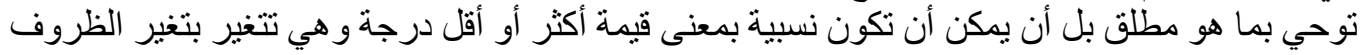

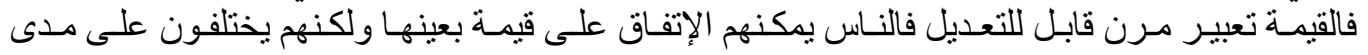
إنطباعها على هذا الثئ.

ـ المعايير والأسس التي تساعد على إختيار المناطق ذات الامكانيات الخاصة "ذات القيمة": 1. أهمبة الموقع.

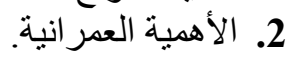




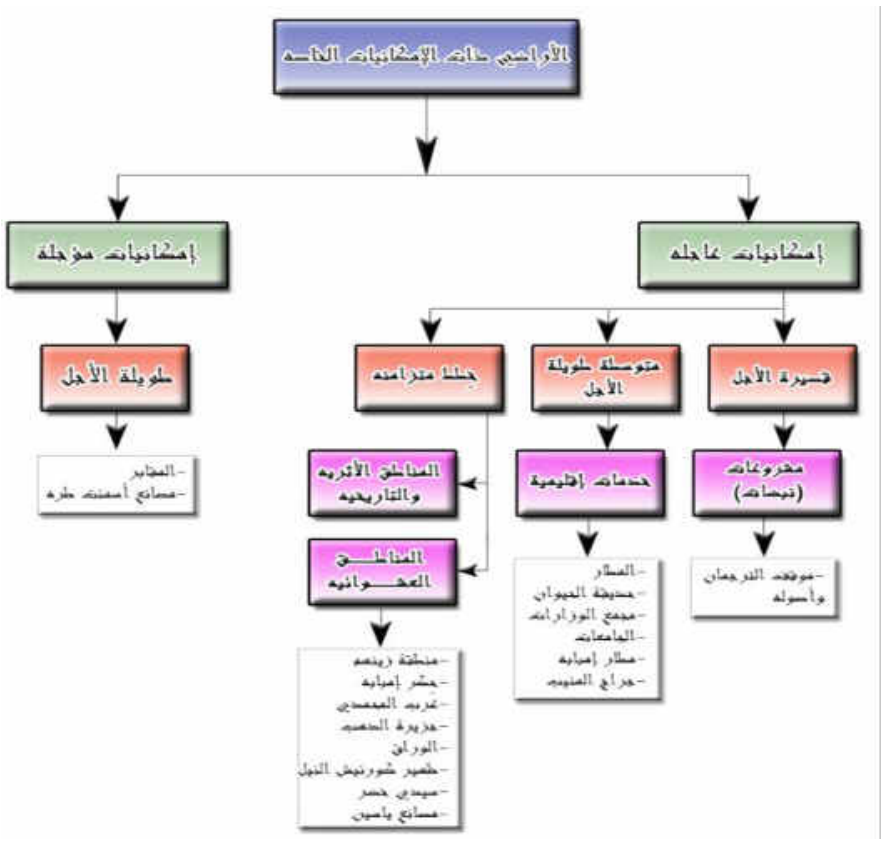

شكل (1): الار اضي ذات الامكانيات الخاصة المصدر: الباحث
3.

4. الأهمية الاقتصادية [6]: من الضروري معرفة الحالة القائمة اللمنطقة ورئة التكاليف

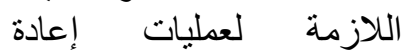
تخطيطها و إدارة العمران بهات العادة

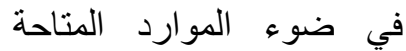
لعمليات إدارة العمر ان ويساهم هذا المعيار في تحديد المناطق العيق ذات الاولوية الاولى لعملية لعنية

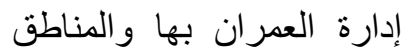

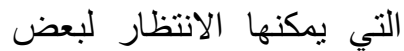

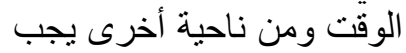
النظر بعين الاعتبار إلى القيمة الاقتصادية

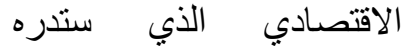
المنطقة بعد إعادة تأهيلها كحافز أومورد يمكن أن يساهم في إدارة العمران للبقدية

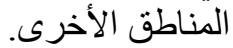

5.

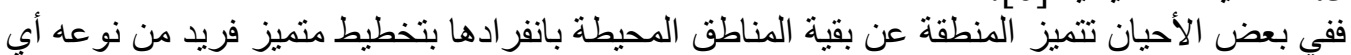

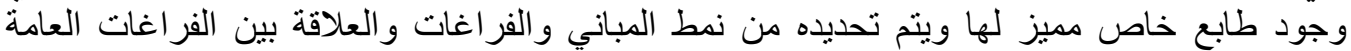
و الخاصة و الاشكال و الالوان و المو اد المستعملة في البناء.

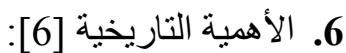

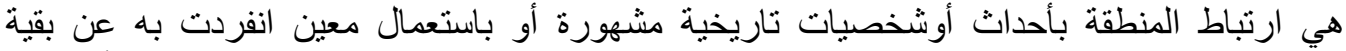

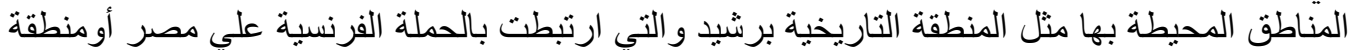

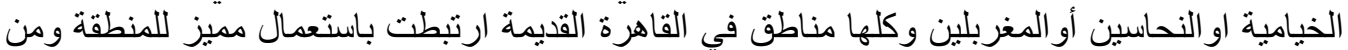

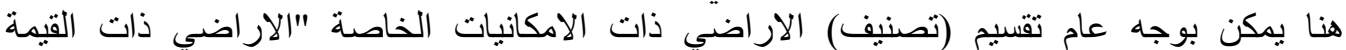
العمر انية" و التي تعتبر أساس الدر اسة التطبيقية.

\section{2 النظريات المعنية بالتركيب الوظيفي والمكاني لأستخدمات الار اضي الحضرية [7]:}

10202 نظرية النمو المركزى (Concentric Zonal):

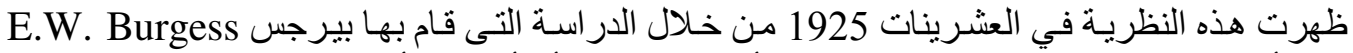

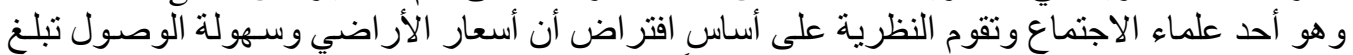

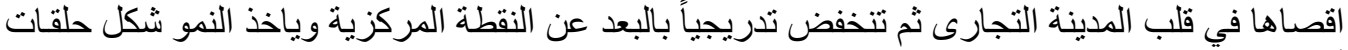

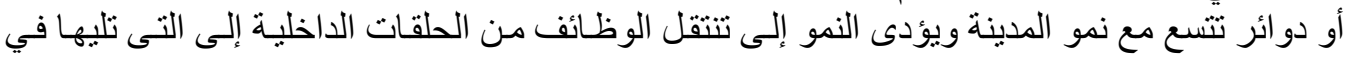
اتجاه الخارج وتتكون من: 


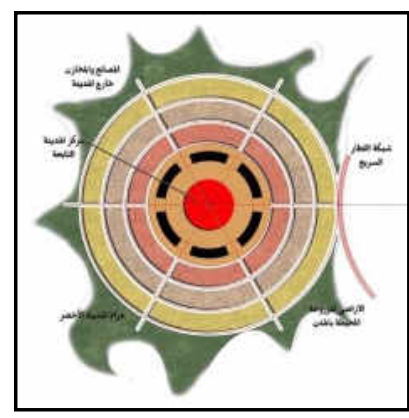

شكل (2): نظرية النمو المركزي المصدر: الباحث

• حي الأعمال المركزية: قلب المدينة النابض اقتصادياً وثقافياً

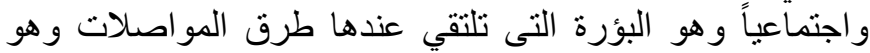

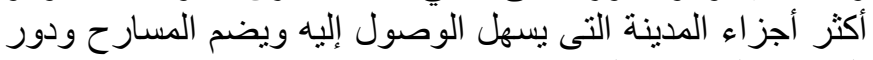

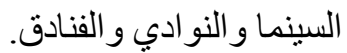
• المنطقة الانتقالية: تختلط فيها استخدامات الأراضي وتسودها

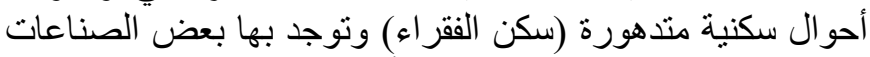
الخفيفة التى كانت في منطقة النواة الأصلية.

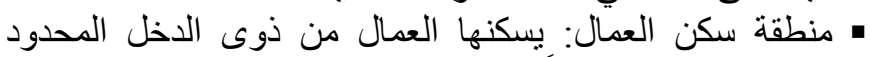
للقرب من اعمالهم توفير اً لنفقات الانتقال.

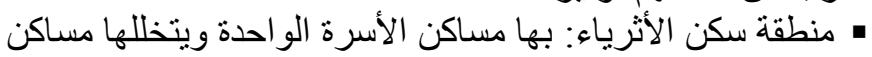

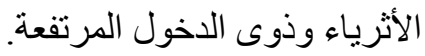
• المنطقة الهامشية: تقع عادة منفصلة عن المنية المنطقة المبنية الرئيسية

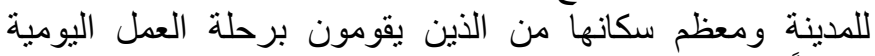

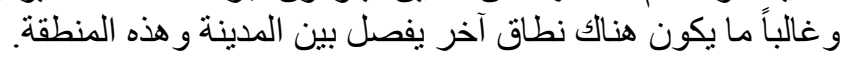

\section{2 نظرية القطاعات (Sectors Theory):}
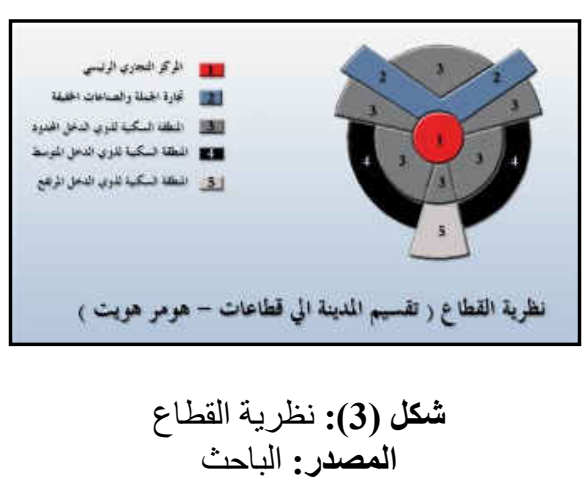

ظهرت نظريـة القطاعات على يد (Homer Hoyt)

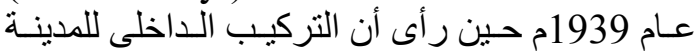

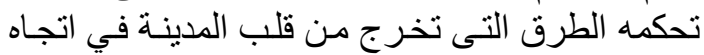

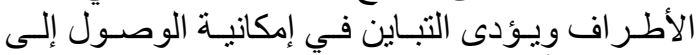

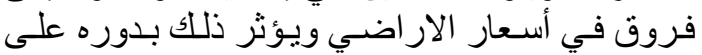

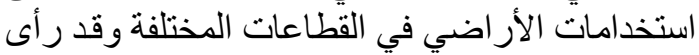

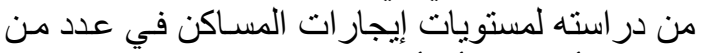

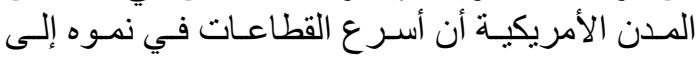

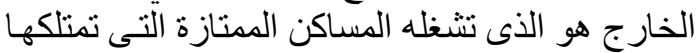

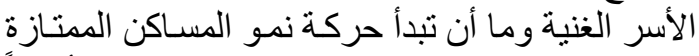

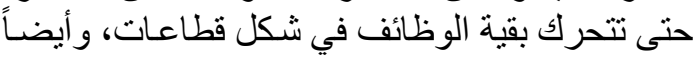

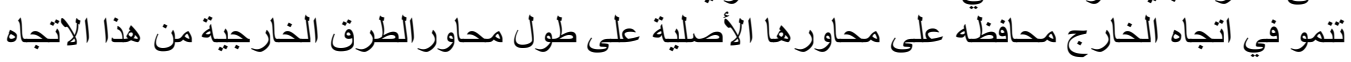
تليها بقية الاستخدامات.

\section{2 نظرية النوايات المتعددة (Multiple Nuclei):}

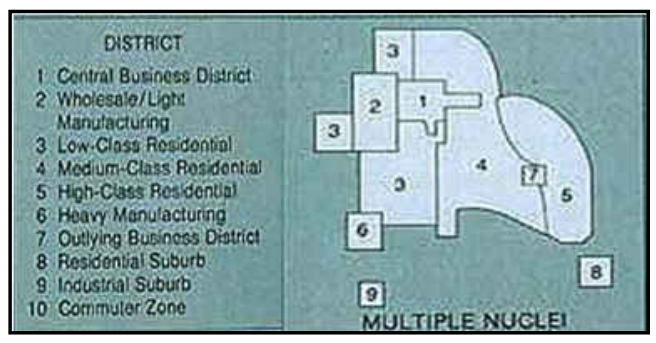

شكل (4): نظرية النوايات المتعددة
ظهرت هذه النظريات عام 1945م كتعديل على النى

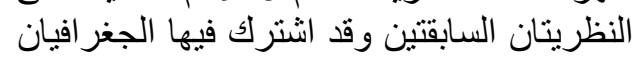
الأمريكيان تشونى هاريس و وإدوارد ولئن ولمان وقد لاحظ الكاتبان (Harris and Ullman)

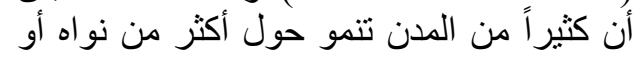

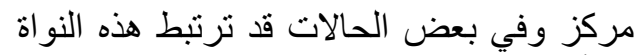

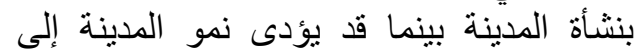

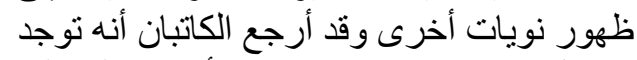
عوامل هامة مرتبطة بطبيعة الأنشطة المختلفة تؤدى إلى وجود نواة مستقلة وأحياء متباينة يمكن تلخيصها في النقاط التالية: 


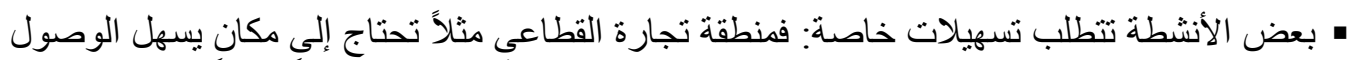

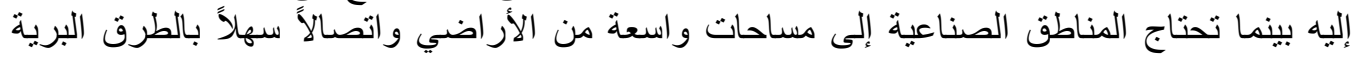
و البحرية و السكك الحديدية.

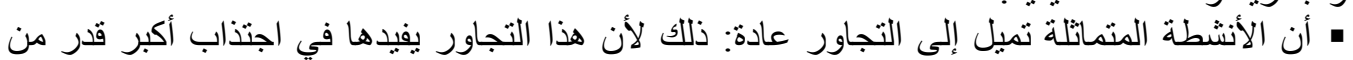

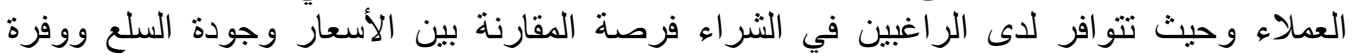

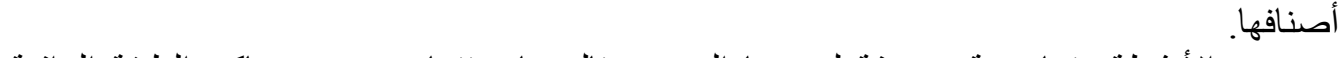

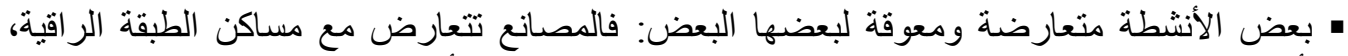

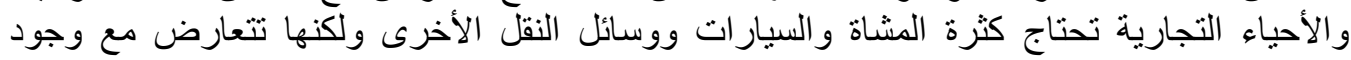

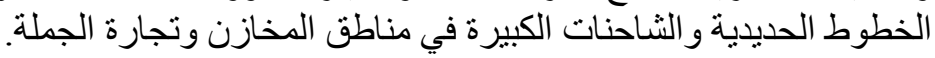

\section{2 توطن الاستخدامات الوظيفية الحضـــــرية [12،13]:}

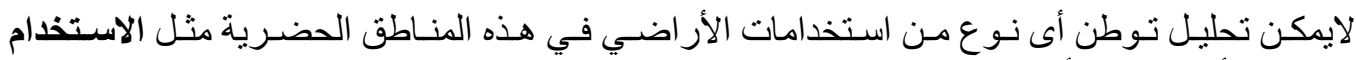

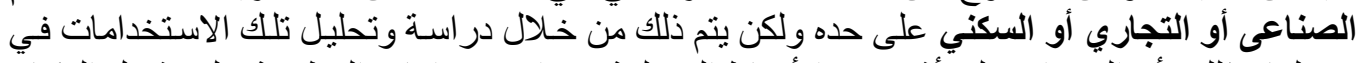

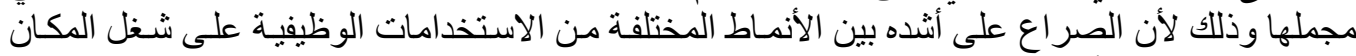
في المدينة بالإيجار أو الملكية.

10302العوامل الحاكمة في توطن الأستخدامات الوظيفية داخل المناطق الحضرية:

\section{2 نظرية عارض الإيجارات (Bid Rent):}

تقرر النظرية أنه من بدفع أكثر يشغل المكان في المنطقة الحضرية وتعد القيمة الإيجارية متغيراً هاماً

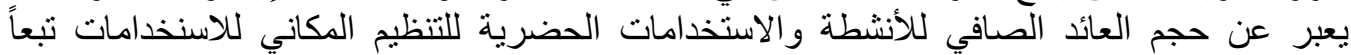

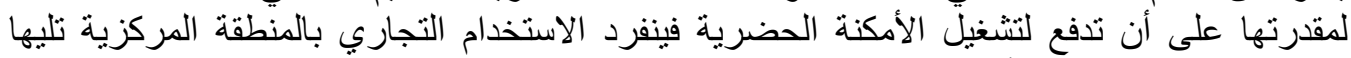
الصناعات بالاتجاه نحو الأطر اف المدينة وتظهر الوظيفة السكنية التى تحتل هو امش المنطقة الحضرية.

\section{2 النموذج العام لاستعمالات الأراضي الحضرية (Van Thune):}

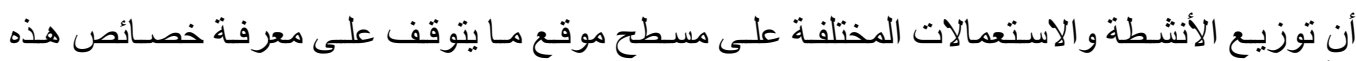

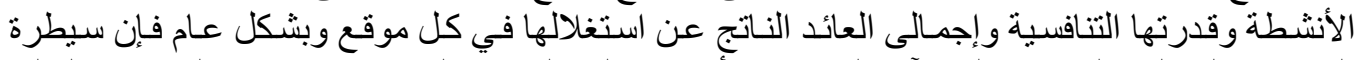

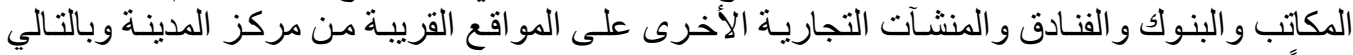

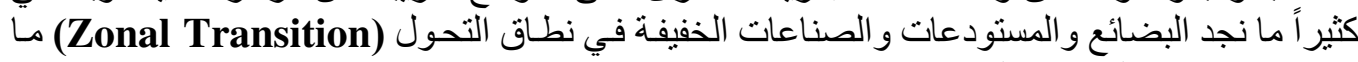
بين الاستعمالات السكنية والتجارية.

\section{2 توطن الأنشطة التجارية والخدمية:}

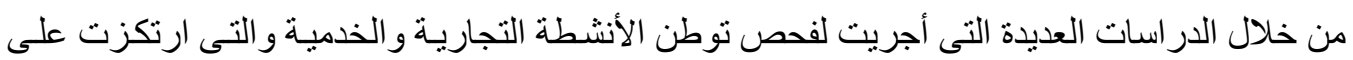

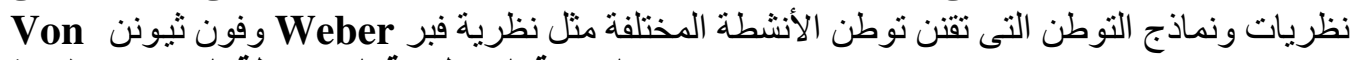

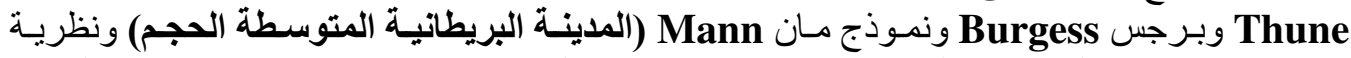

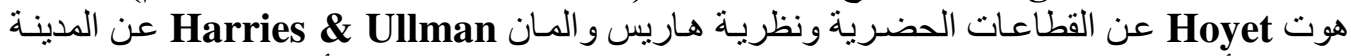

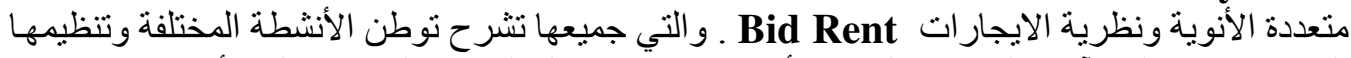

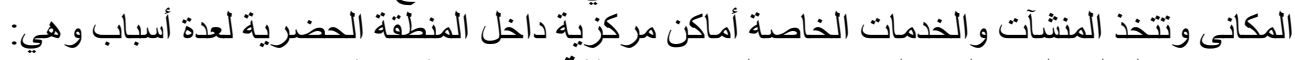

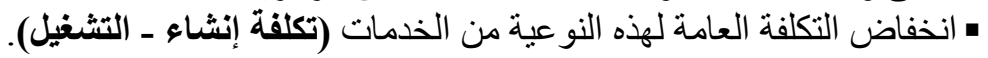

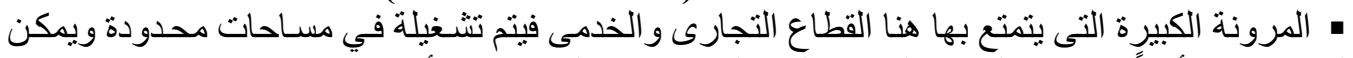
له الامتداد رأسياً وارتفاع العو ائد الصافية لهذا القطاع دون القواع القطاعات الأخرى. 


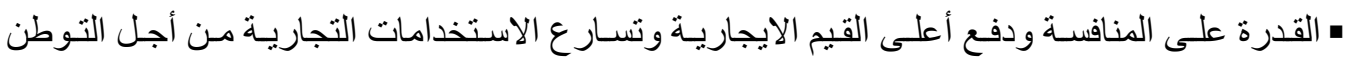

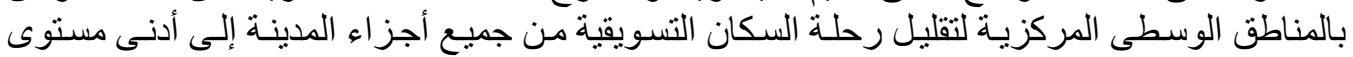

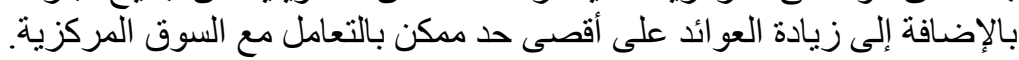
30302 أنماط توطن الأنشطة والخدمات بالمدن الماندئ المصرية:

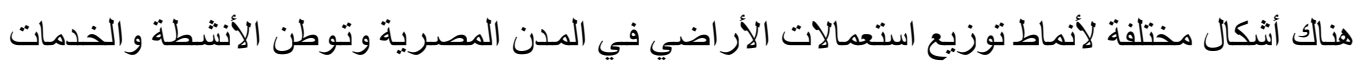

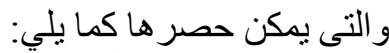

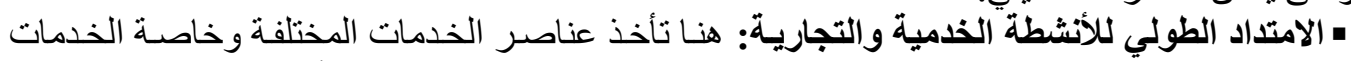

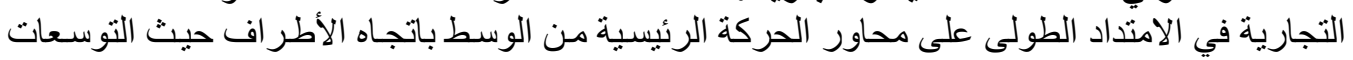

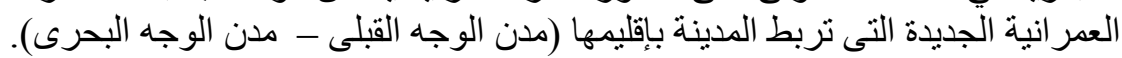

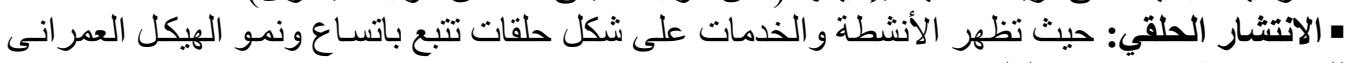

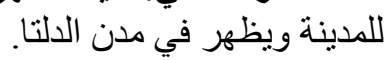

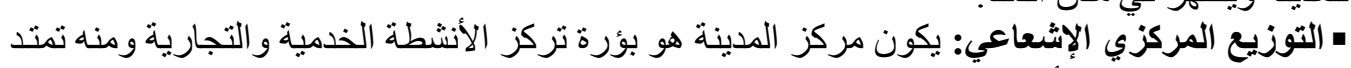

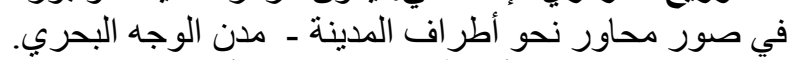

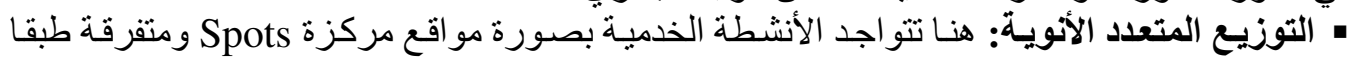

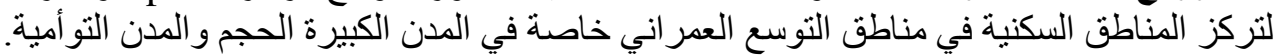

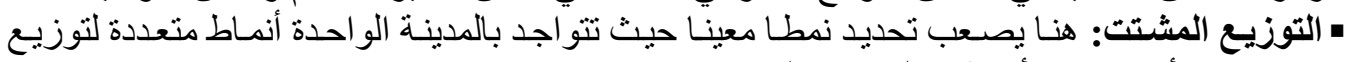
استعمالات الأر اضي و الأنشطة مثل مدينة القاهرة.

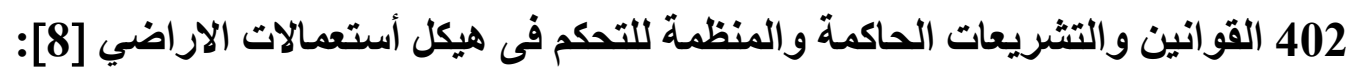

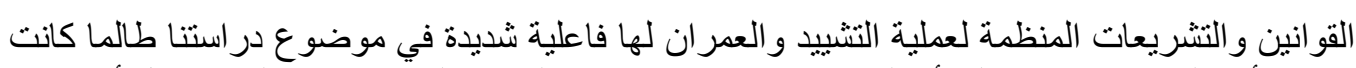

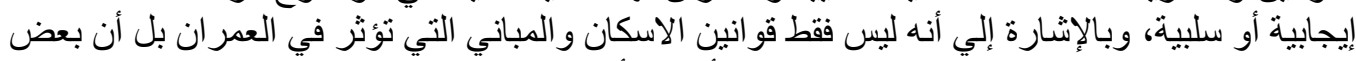

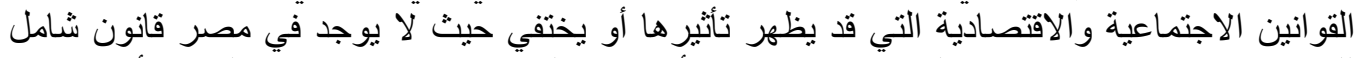

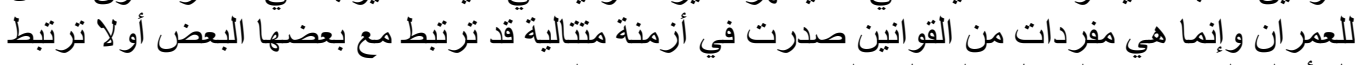

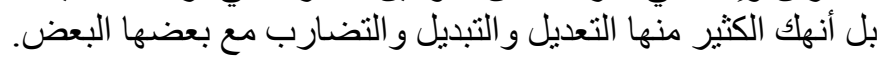

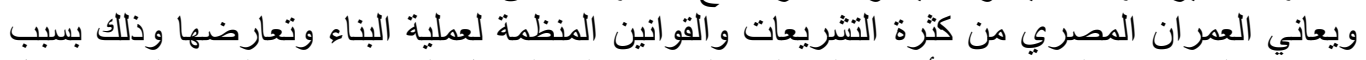

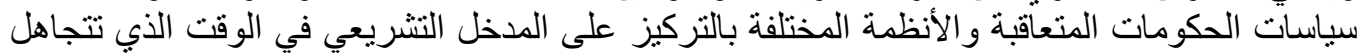

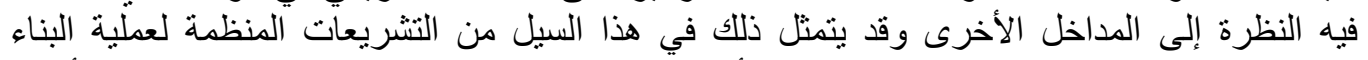

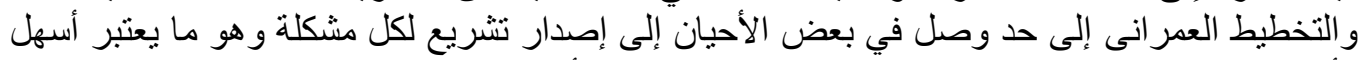

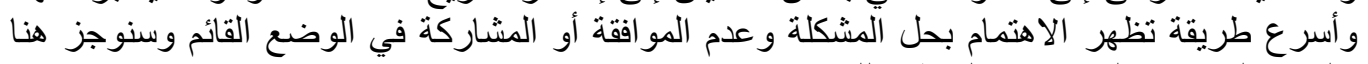
سلبيات القو انين والتشريعات المنظمة للعمر ان.

\section{2 سلبيات القوانين والتشريعات المنظمة للعمران:}

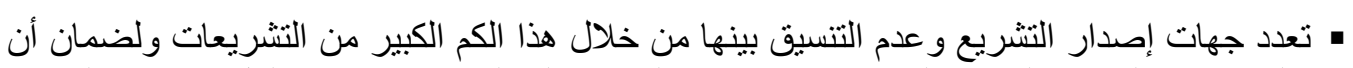

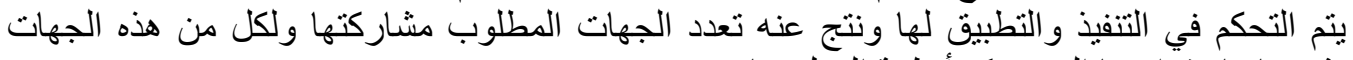
تشريعاتها وقو انينها التي تحكم أنظمة العمل بها.

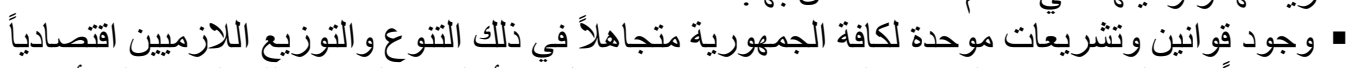

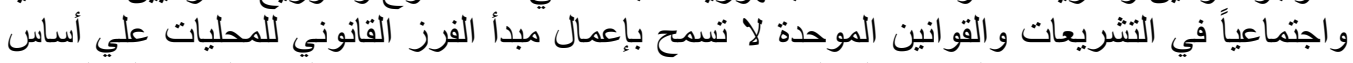

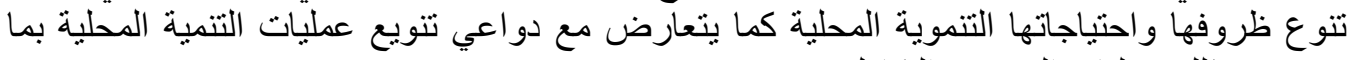

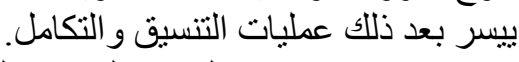
" اليشدم وضوح بعض المواد بالقو انين المنظمة لعملية البناء يمكن أن يتم تفسير ها بالعديد من التفسيرات 


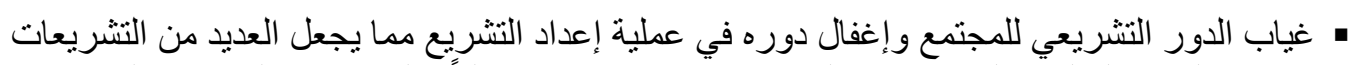
بعيدة عن الو اقع الفعلي والتناسب مع البيئة الاجتماعية ويؤية وأثر سلباً علي اقتناع المجتمع بالتشريعات

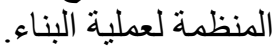

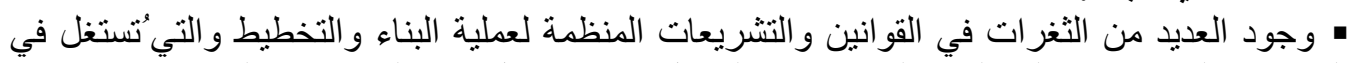

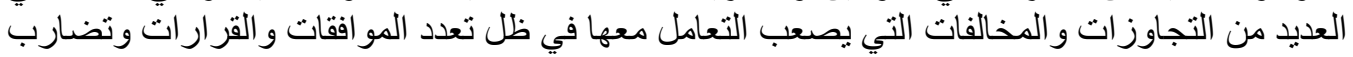

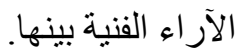
• تعتمد الأحكام القضائية في مجال تتظيم إجراءات ألقاء عملية البناء و التخطيط العمر انى في الأساس علي

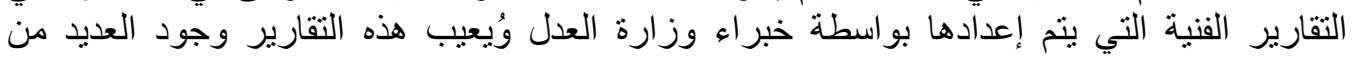
المشاكل نتيجة ضعف الكو ادر القائمة على إعداد هذه التقارير.

\section{2 التشريعات المنظمة لهيكل استعمالات الأراضي:}

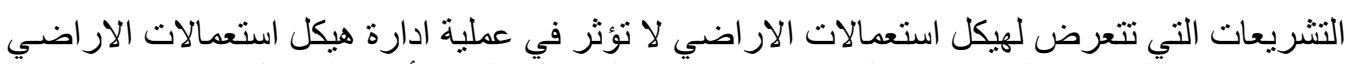

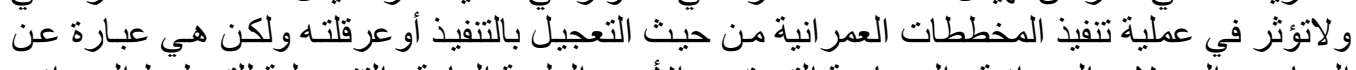

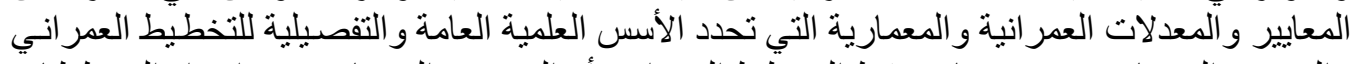

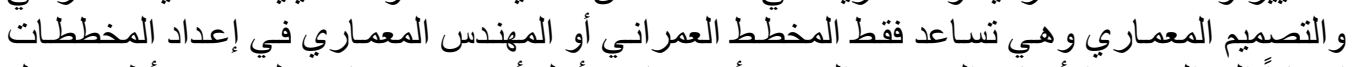

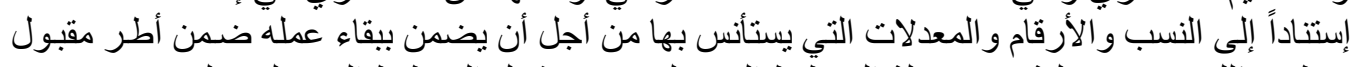

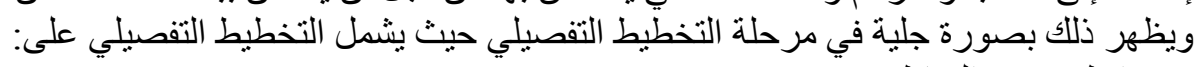

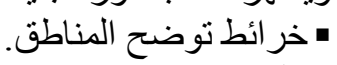
• التقارير وهي عبارة عن إشتر اطات هذه المناطق وتنقسم تلك الاشتر اطات إلى قسمين:

\section{2 أشترطات أستعمال الاراضي:}

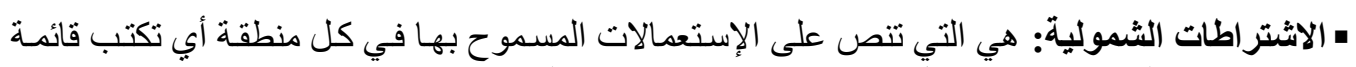

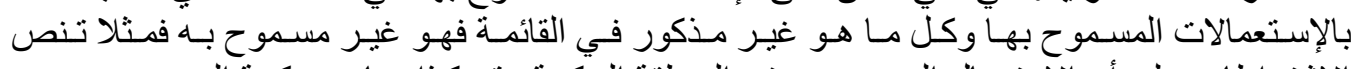

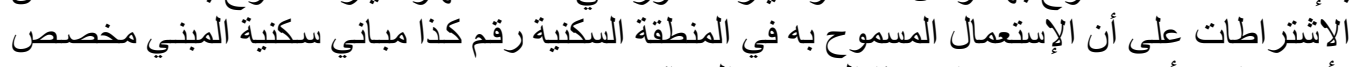

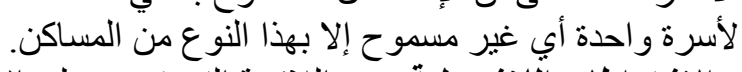

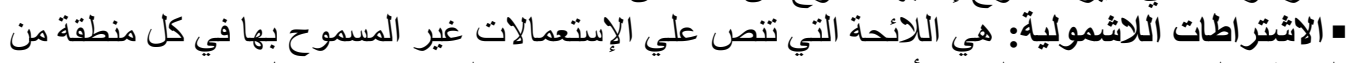

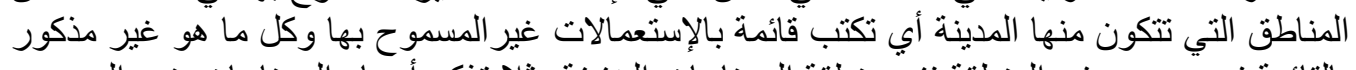

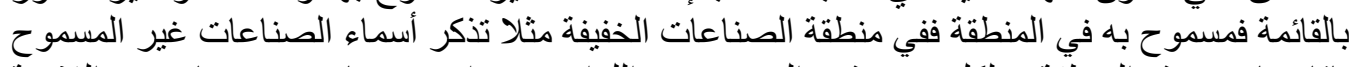

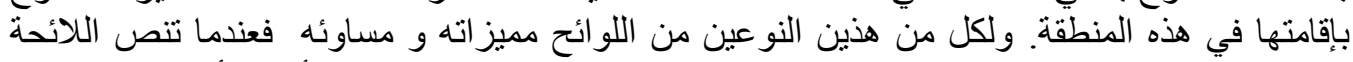

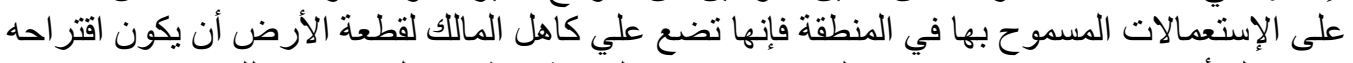

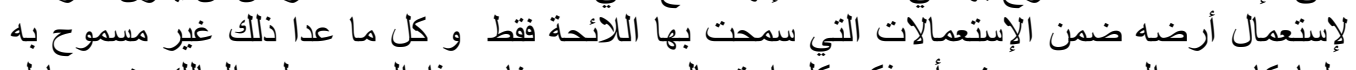

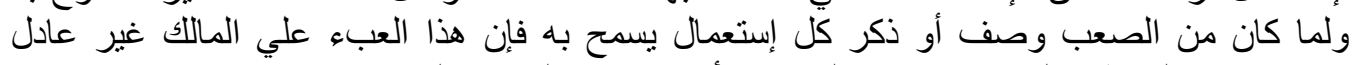

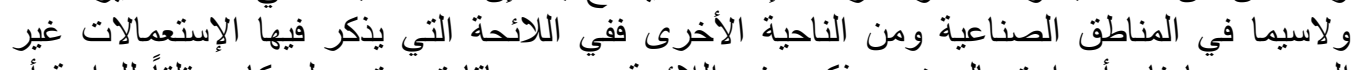

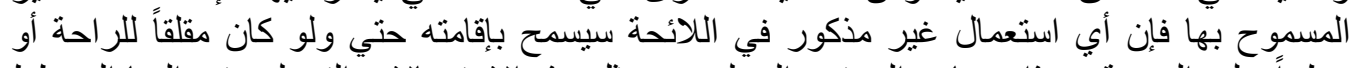

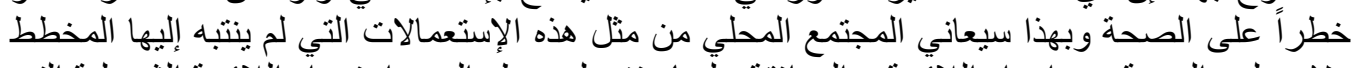

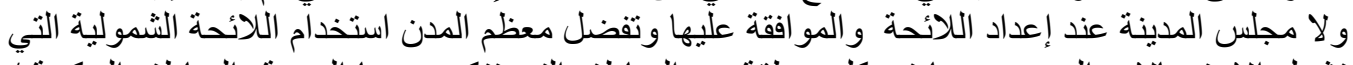

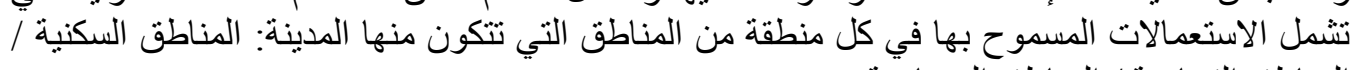

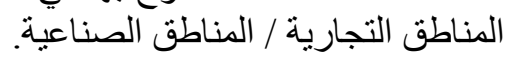

\section{2}

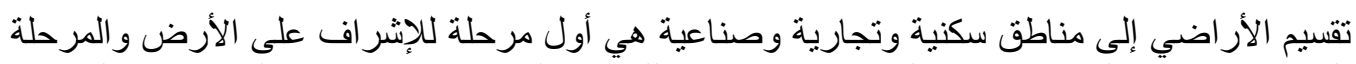

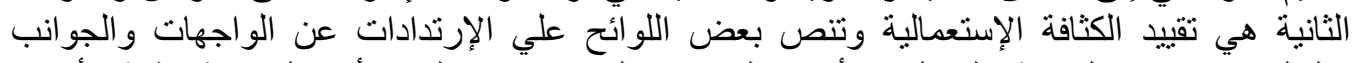

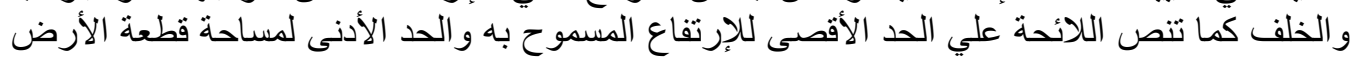




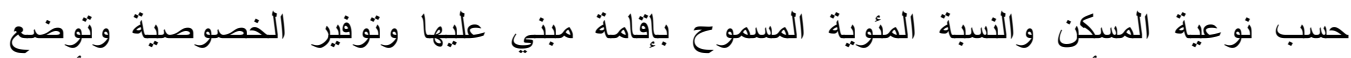
الاشتراطات على أساس الكثافة السكانية الصافية والإستعمالات المساعدة المأية على نفس قطعة الأرض كالمساحات المفتوحة. 502 العوامل المؤثرة على التركيب الوظيفي لاستعمالات الاراضي في المدينة[9]:

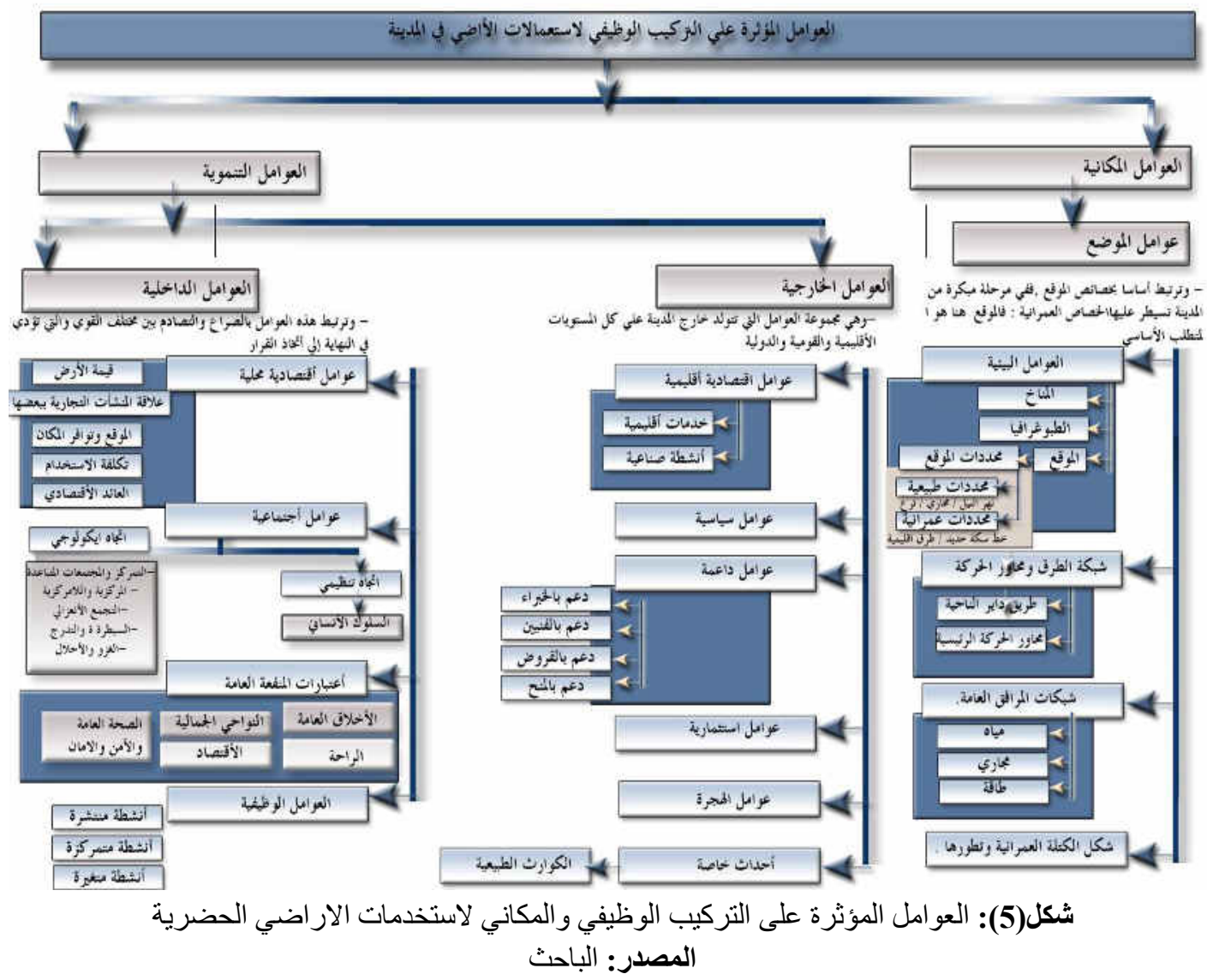

10502 شرح العلاقة بين المجموعات الرئيسية للعوامل المؤثرة على التركيب الوظيفي

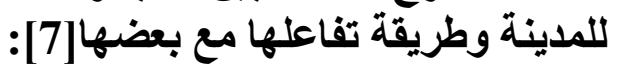

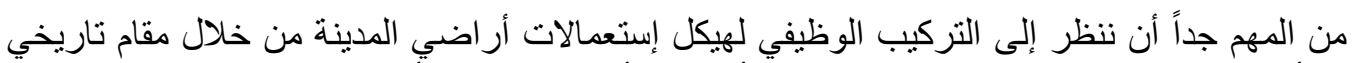

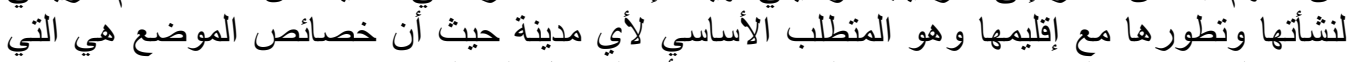
تجذب العملاء من الخارج وفي معظم الحالات نجد أن العو امل الداخلية (Endogenous Factors) قد التي

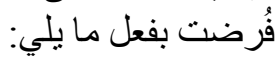
• العوامل الخارجية (Exogenous Factors). • ميزات وخصائص الموضع (Advantages of Site Characteristics). و إنه كنتيجة لنمو المدينة أو عجز المدينة تتبدل كل من:

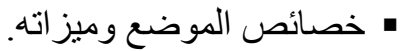

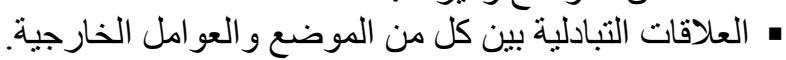




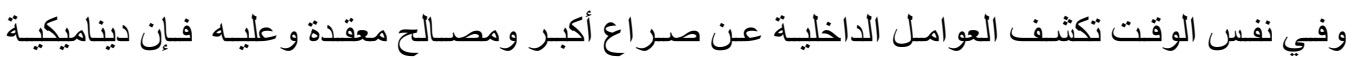

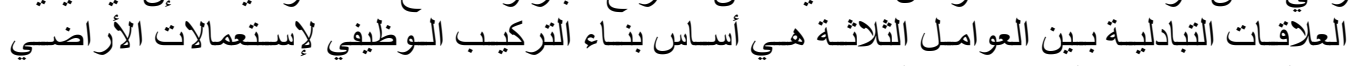
في المدينة وتتتم هذه العلاقات كما يلين العالي:

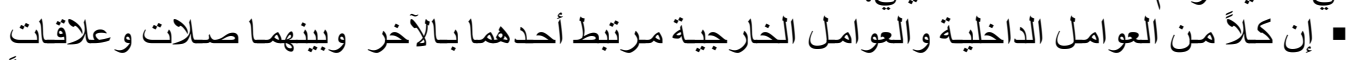

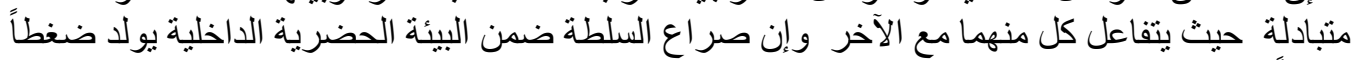

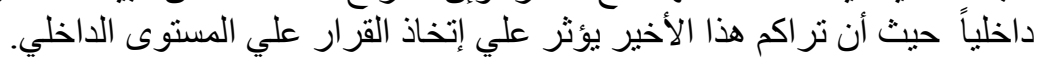

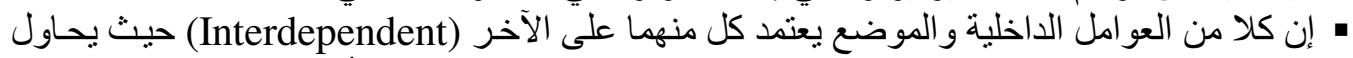

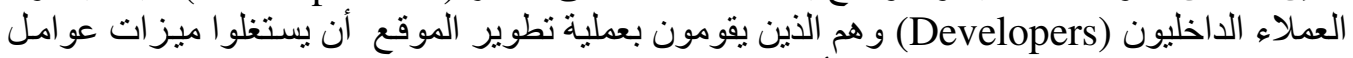

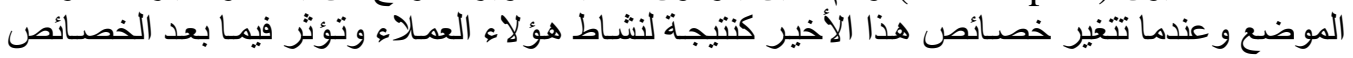
الجديدة على مصالحهم و اهتماماتهم.

2.5.2 2.2 1.2.5.2 العوامل البيئية:

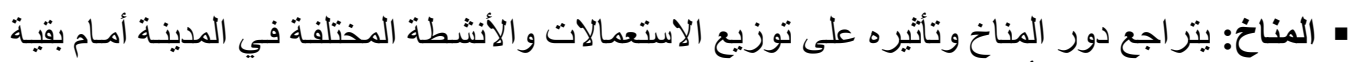

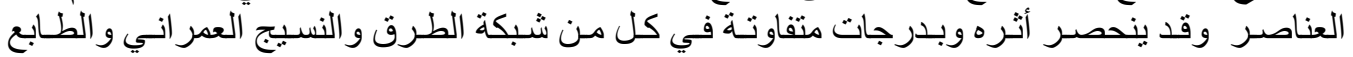

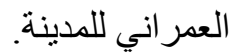

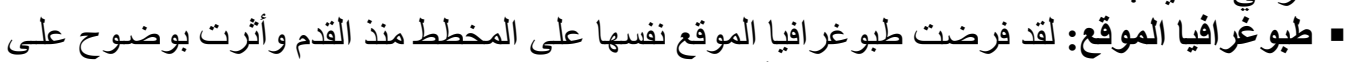

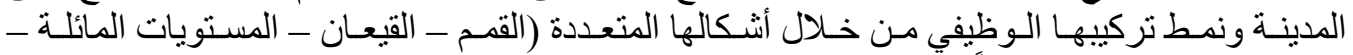

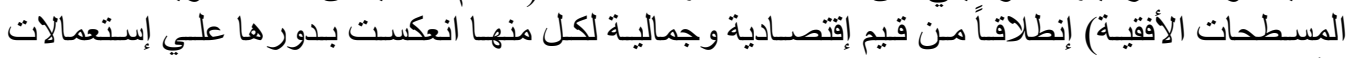

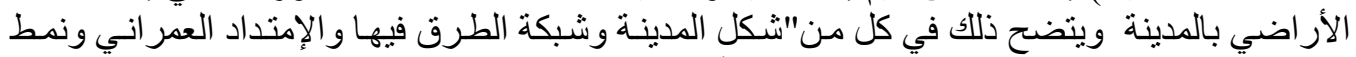

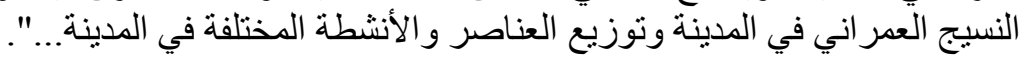

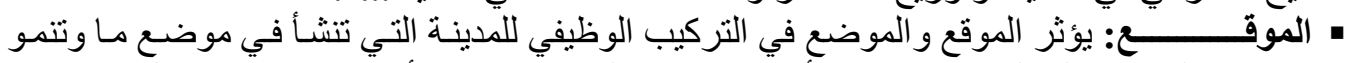

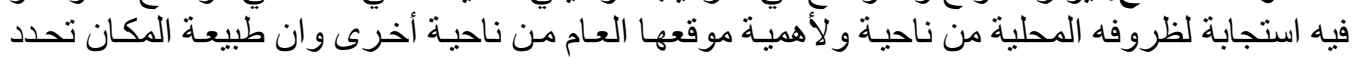

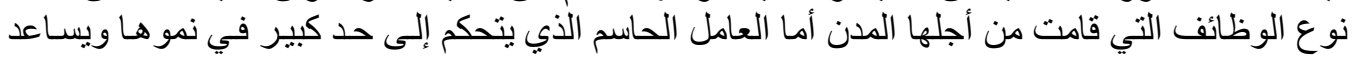
على تغيير وظائفها فيما بعد هو التون الموقع.

2.2.5.2 تأثير شبكات الطرق ومحاور الحركة علي إستعمالات أراضي المدينة:

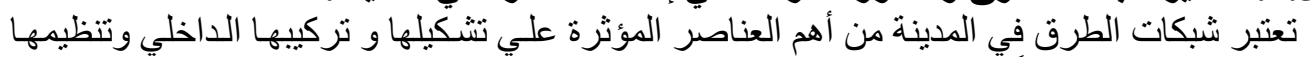

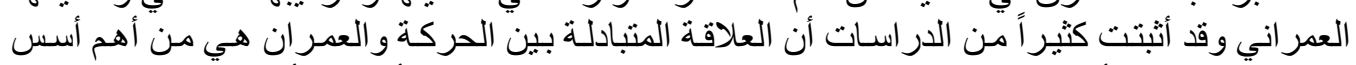

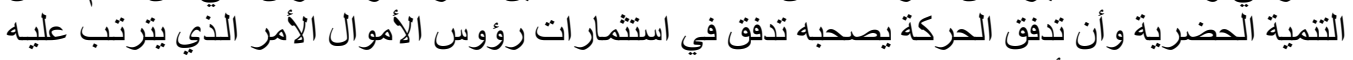

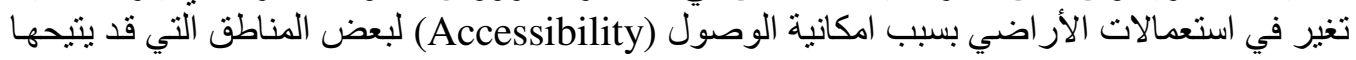
انشاء طريق جديد.

\subsubsection{2 تأثثير شبكات المرافق العامة:}

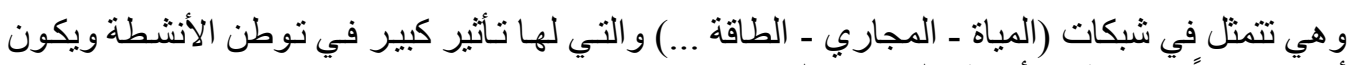
أثرها محدداً في توطن الأنشطة السكنية و الخدمية.

\subsection{2 العوامل الاخلية (Endogenous Factors):}

\subsubsection{2 العوامل الأقتصادية الاخلية (محلية) وأثرها علي استعمالات الأراضي:}

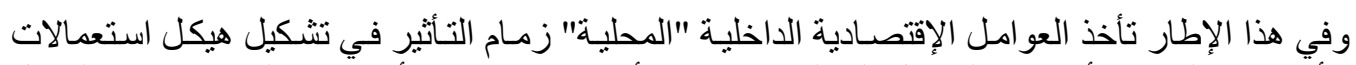

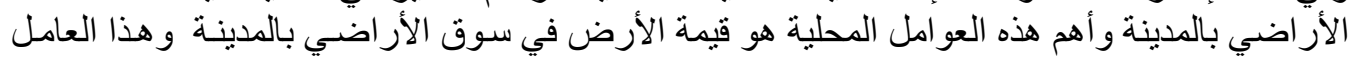


ذو تأثثير بالغ في تحديد مو اقع مختلف الوظائف العمر انيـة Urban Function و استعمالات أر اضي المدينة.

\subsubsection{2 قيمة الأرض وتأثثرها علي استخدام الأرض:}

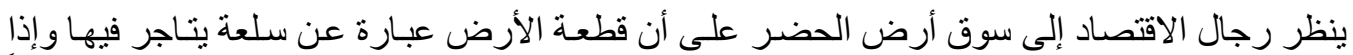

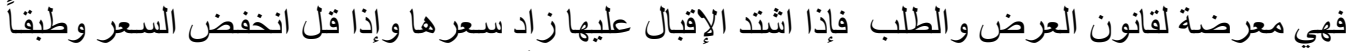

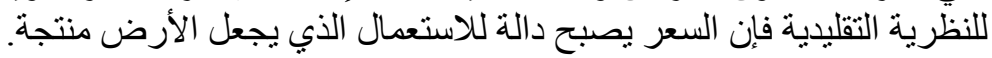

\subsubsection{2 تباين أسعار الأراضي وتأثيرها على نمط توزيع الاستخدامات:}

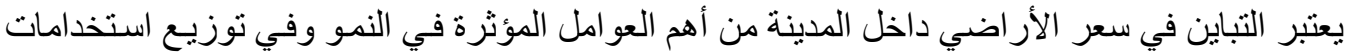

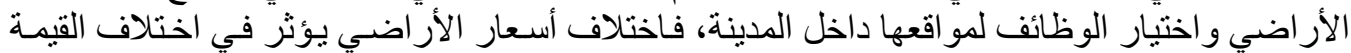

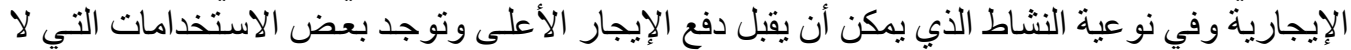
يمكن منافتنها في هذا الصدد و هي الاستخدامات التي تعطي أعلى عائد يبرر دفع إيجار الآن مرتفعة.

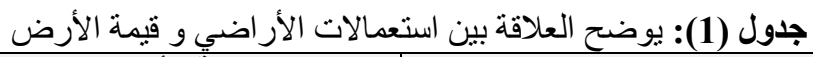

\begin{tabular}{|c|c|}
\hline قيمة الأرض Land Values & Land Use Pattern استعمالات الأراضي \\
\hline • أ أعلى قيمة من أى منطقة أخرى بالمدينة. & • - المنطقة المركزية. \\
\hline • ل قيمة الأرض كتلال متر اكمة. & • - مناطق الصناعة. \\
\hline 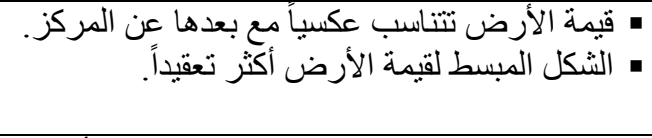 & 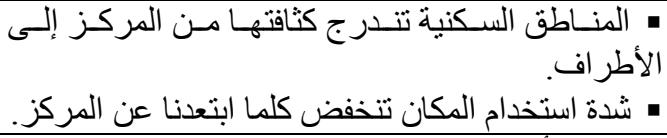 \\
\hline يوقع تؤثر في قيمة الأرض. & • قيمة الأرض تؤثر في كثافة استخدام الموقع. \\
\hline
\end{tabular}

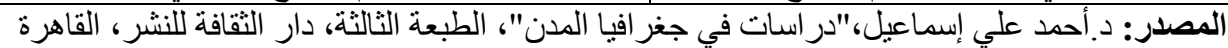
1985

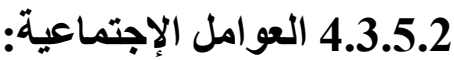

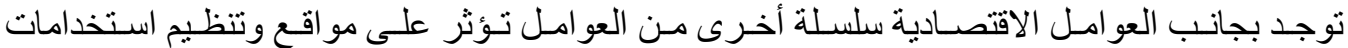

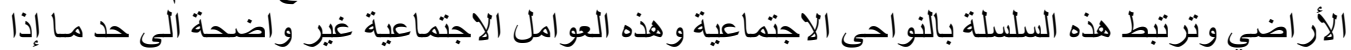

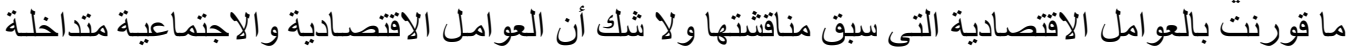

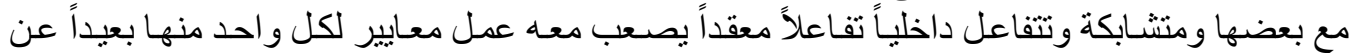
الآخر ويمكن در اسـة أثنر العو امل الاجتماعية في نتشكيل هيكل استعماعلات أر اضـي المدينـة من خـلال

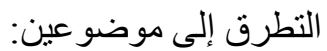

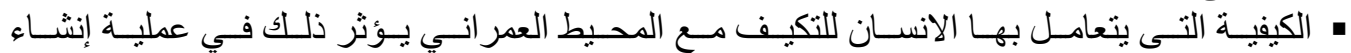

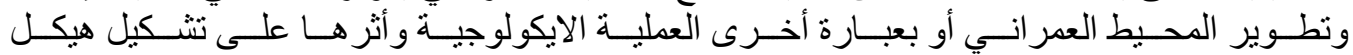
استخدام أر اضير المير المدينة. • كيفية تأثير القيم و المثل و السلوكة الإنساني في تشكيل هيكل استخدام أراضي المدينة.

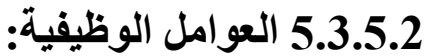

يتأثر التوزيع المكاني لنوعيات أنشطة الخدمات التجارية بالتصنيف الوظيفي لكل سلعة يقدمها هذا النشاط

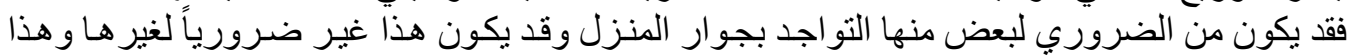
بدوره يُحدد الموقع المناسب لتوطن هذه النوعية من الخدمات التجارية سواء في المو اقع المركزية أو غير

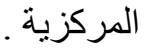


4.5.2 العوامل الخارجية (Exogenous Factors): 1.4.5.2 العوامل الإقتصادية الخارجية (الإقليمية):

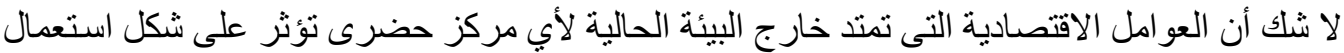

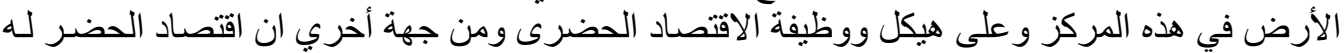

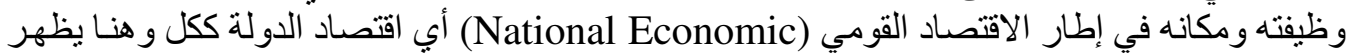

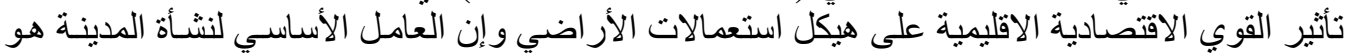

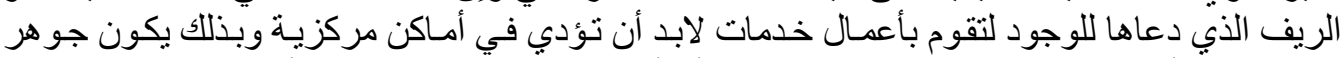

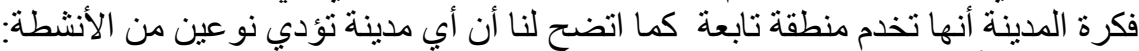

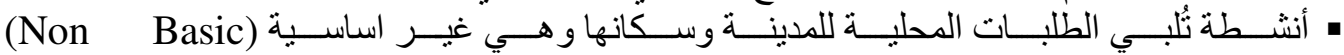
وتعتبر خادمة للمدينة (City Serving).

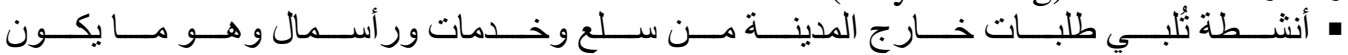

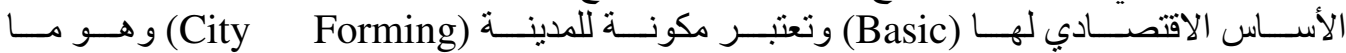
نسميه بالدور الاقليمي للمدينة.

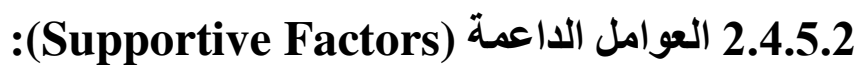
قد يكون دعم بالخبراء والفنيين أودعم بالقروض والمناء المنح (نتج عن القروض التي منحتها أمريكا عام

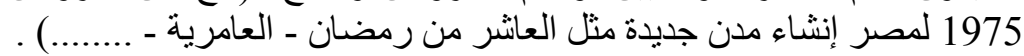

3.4.5.2 عوامل الهجرة (Migratory Factors)

وقد تضم هجرة رؤوس الأمو ال أو التكنولوجيا أو السكان إلي المدينة وكيفية إنعاكس ذلك على تركيبها الوظيفي.

4.4.5.2 أحداث خاصة (Special Events):

مثل الكو ارث الطبيعية وغير ها.

602 المحدات المؤثرة علي التحكم فى هيكل أستعمالات الأراضي ذات القيمة القيمة

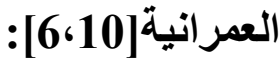

10602

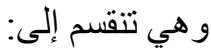
• محددات خاصة بأعمال التتفيذ و الاستثمار بين القطاعين العام و الخاص.

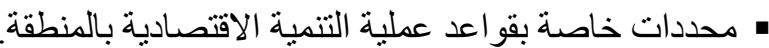
ويمكن تحديد مصـادر تمويل مشرو عات ادارة العمران (إعادة تشكيل هيكل استعمالات الار اضي) في

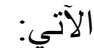
• التمويـل الـذاتي: المقصـود بذاتيـة تمويـل مشـروع ادارة العمـران هـو البحـث عـن إمكانيـة اسـتغلال

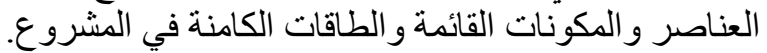

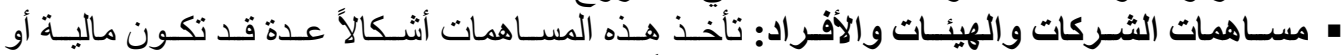

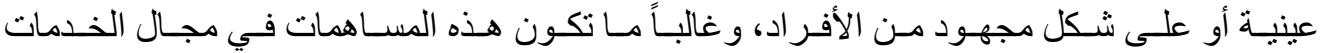

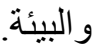

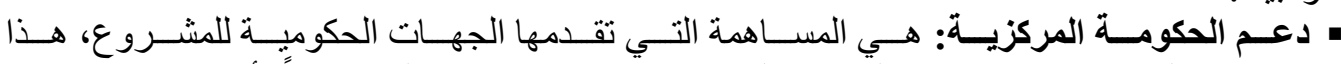

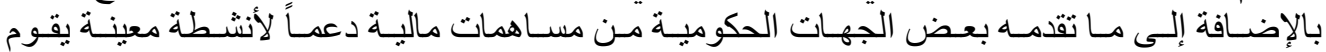
بها العاملون على المشروع في منطقة المشروع. 
• مسـاهمات خارجيـة دوليـة: عبـارة عـن مسـاهمات مـن جهـات دوليـة منـل منظمـات الأمـم المتحـدة

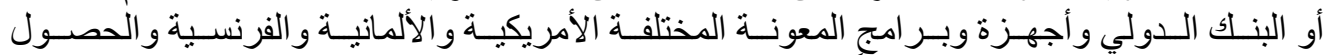

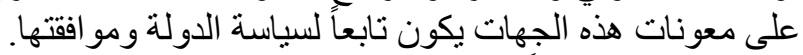

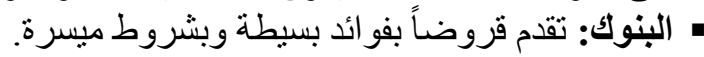

\section{2 المحددات الخاصة بتثوع الجهات المساهمة في مشروع ادارة العمران:}

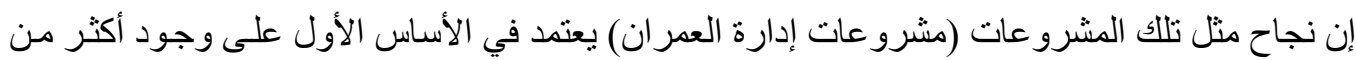

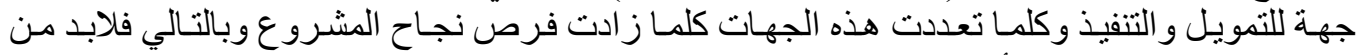
توضيح الادوار التي يمكن أن تقوم بها الجهات التهات المختلفة.

\section{2 المحددات الخاصة بالمشاركة الجماهيرية:}

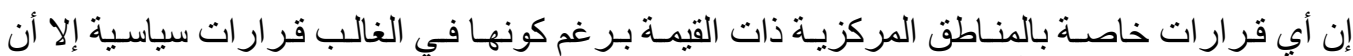

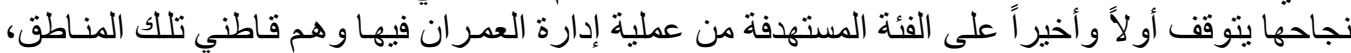

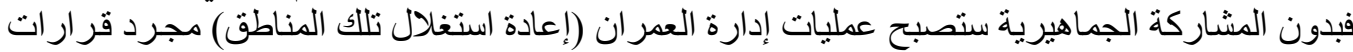
وتوصيات لن تدخل قالب التنفيذ.

\section{2}

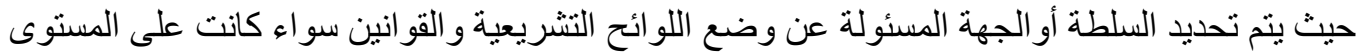

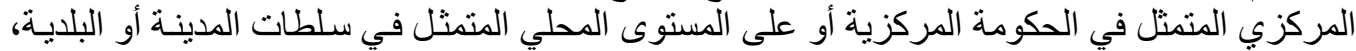

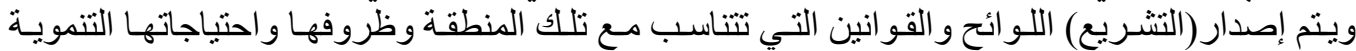

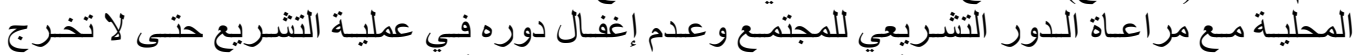

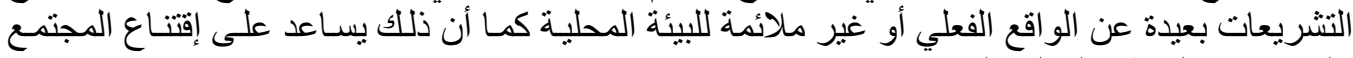

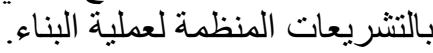

\section{2}

من أخطر العو املـ السلبية التي تؤثر في المشـرو عات العمر انيـة خاصـة مشـاريع إدارة العمر ان (إعـادة

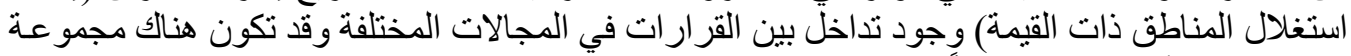

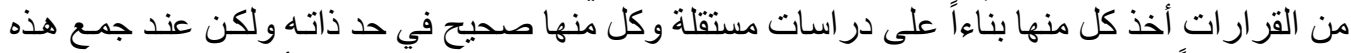

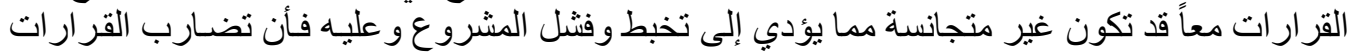

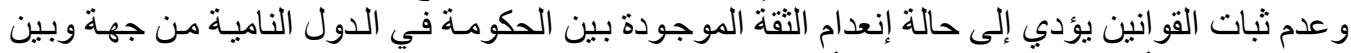

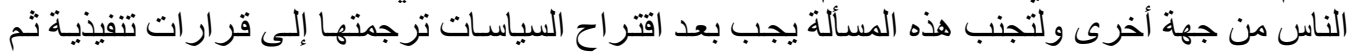

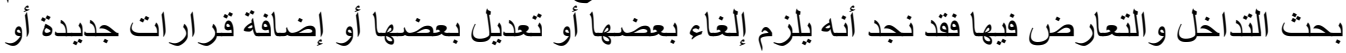
تقديم قر ار على آخر.

\section{2 المحددات الخاصة بالخدمات التي تفتقرها المنطقة:}

تعتبر من أهم المحددات التي تحكم عملية إدارة العمران والتي لها أكبر الأثر في توجيه هيكل استعمالات

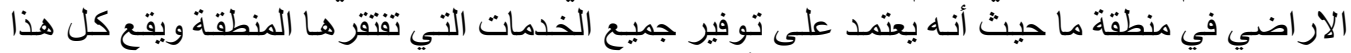

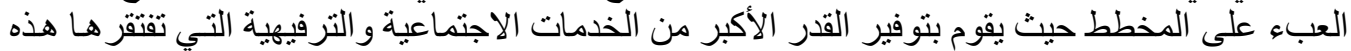

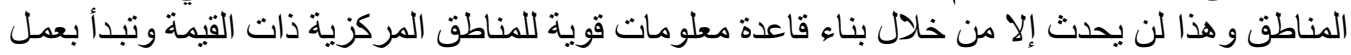

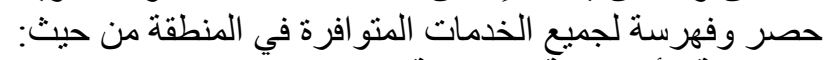

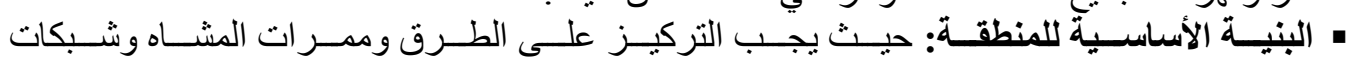
الصرف الصحي و التغذية و الكهرباء و الغاز و الاتصالاتهات. 


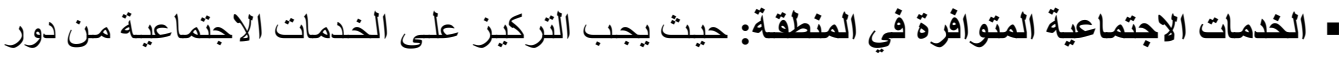

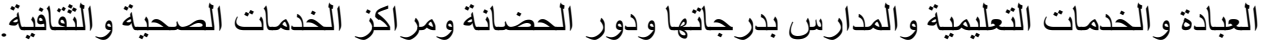

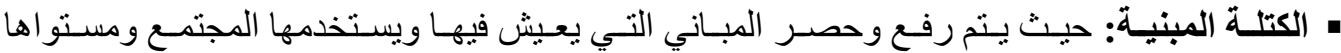
المعماري (مناسبة / غير مناسبة).

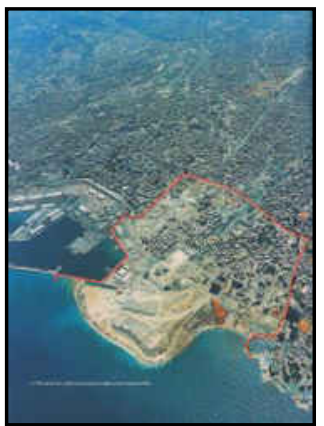

شكل (6): الموقع العام لمنطقة

$$
\text { وسط بيروت المبع }
$$

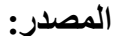

www.lilwatan.com • المجتمع في حد ذاته: هو يشمل شقي مني المجتمع الاقتصادي و الاجتماعي. 702 التجارب العالمية للتحكم في أستعمال الأراضي لرفع كفاعة العمران:

1.7 .2 تجربة تنمية و إعادة إعمار حي وسط بيروت (14](BCD)]:

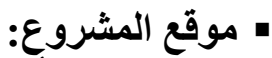
يتضمن المشروع أرض تصنل مسطحها إلى 1.8 مليون م2 ويقوم على ويلى

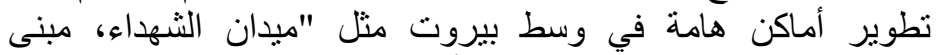

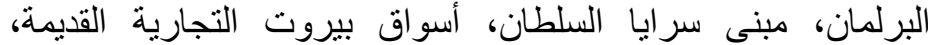

المناطق التاريخية".

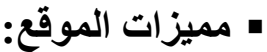
1. يتضمن مساحة شاسعة من من الأراضي وبه أكثر الميادين و الطرق الطرة

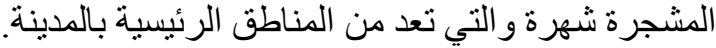

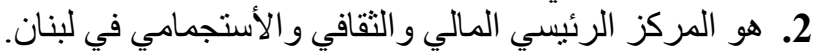

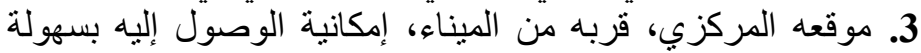

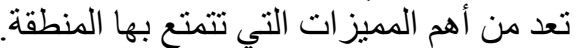

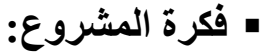
1. إنشاء منطقة مختلطة من أستعمالات الأراضي وتقسيم حي بيروت المركزي و الذي تبلغ مساحته

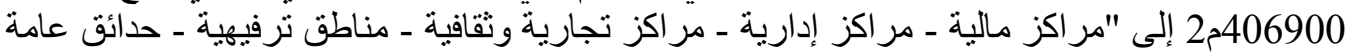

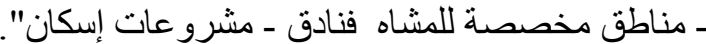

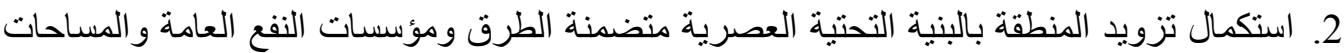
العامة والأشغال البحرية. 3. استصلاح مساحات كبيرة (شاسعة) على البحر تبلغ 608000م2 وتطوير ها لتصبح منطقة نرفيهية

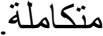

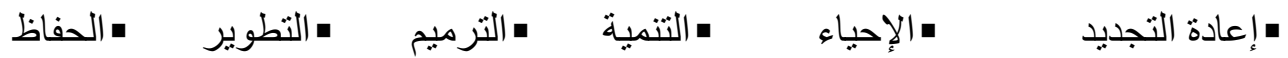
ه السباسات المتبعة لتطوير المنطقة: ـالجهات المشاركة في تطوير المنطقة:

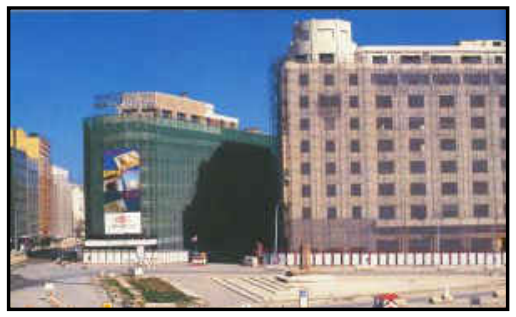

شكل (7): المباني التي تم ترميمها في طريق

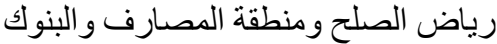
المصدر: www.lilwatan.com

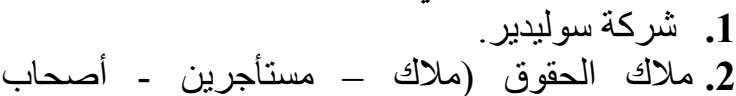
العقار ات المؤجرة) بحي وسط بيروت (مات المون. 3. المو اطنين اللبنانبين و الثركات اللبنانية الخالصة.

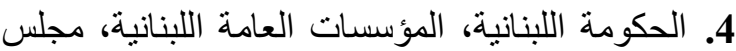
بلدية بيروت. 5. أشخاص لهيزوت أصل لبناني، الجنسيات العربية، 6وألمسات العامة وشبه العامة. 6. المؤسسات و الجامعات الدولية وشبه الدولية. 


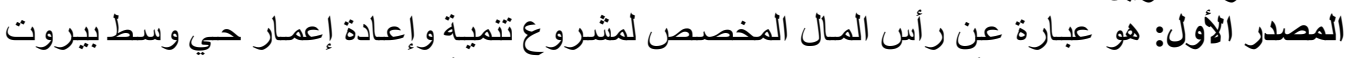

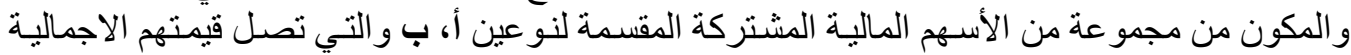

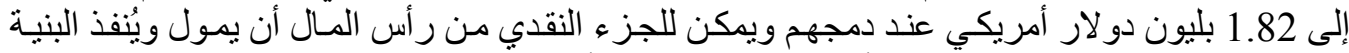

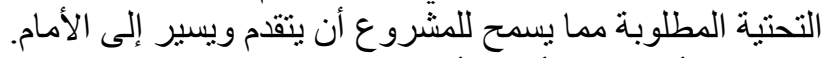

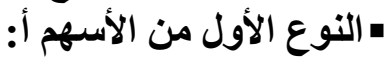
ويتم إصدار ها لملاك الحقوق بحي وسط بيروت والأو الأفر اد و المؤسسات الذين لديهم الحقوق فيه و ذللك مقابل

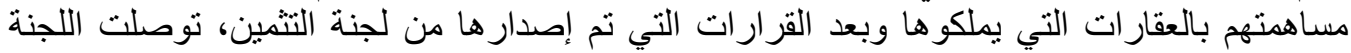

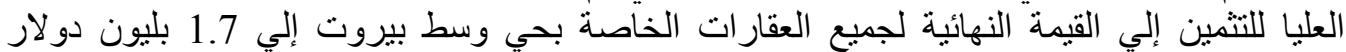

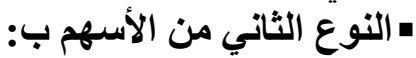

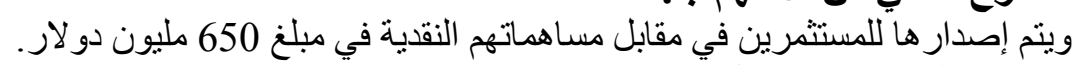

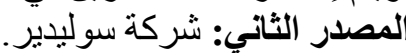

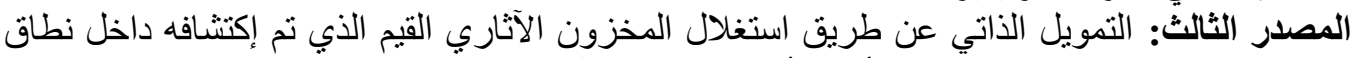

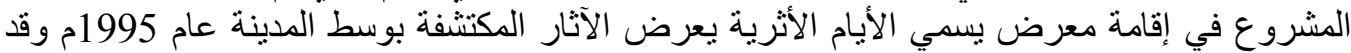
جذب حوالي 122,000 زئر خلئر خلال 15 يوم فقط.

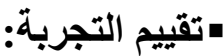

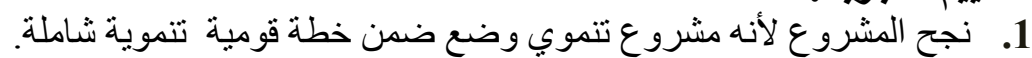

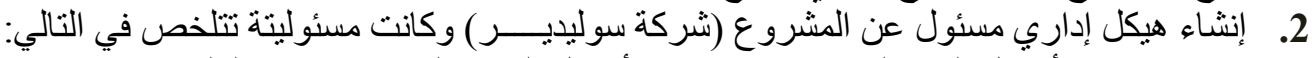

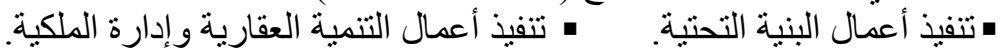

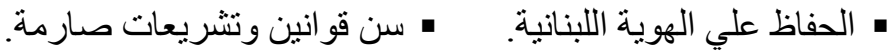
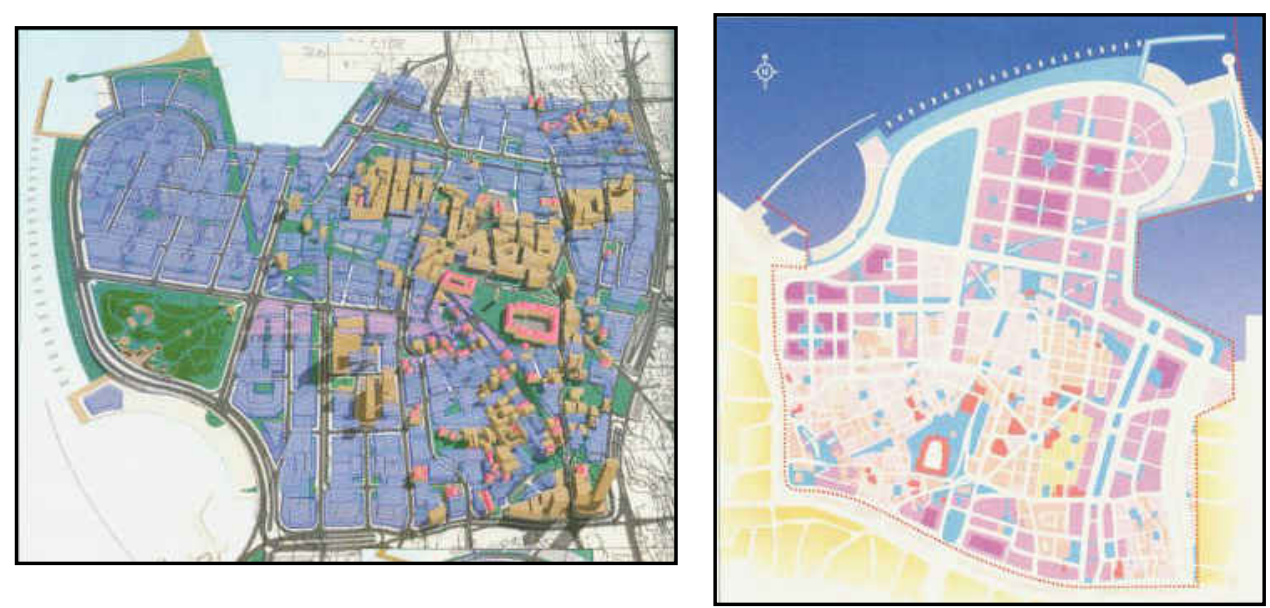

شكل (9): المخطط الرئيسي التقليدي لاستعمالات شكل (8): المخطط الرئيسي لحي وسط بيروت الار اضي يكون في الغالب ثنائي الابعاد ويسبقه العديد الآنيد

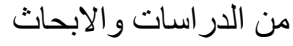

المصدر: www.lilwatan.com 


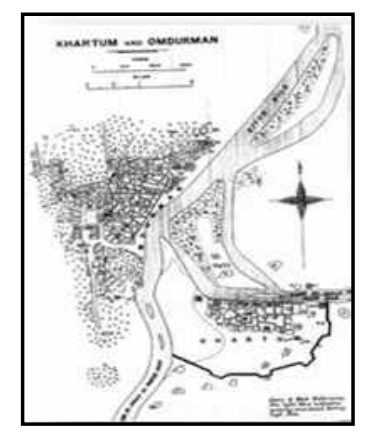

شكل (10): موقع مشروع أرض المقرن

المصدر: www.alsunut.com

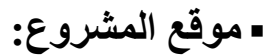

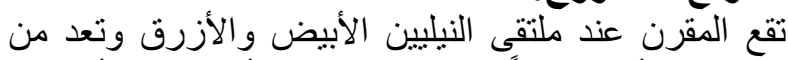

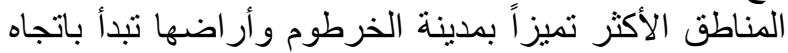
أعلى نهر النيل الأبيض إلى نقطة محددة جنوب التئ غابة أكاسيا

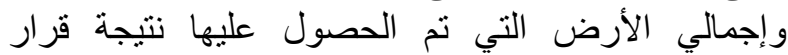
الحكومة هي 1217 فدان وقد تم منح تعويض لملاك الأر اضي.

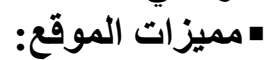

1. الرمز التاريخي للمنطقة حيث تعد واحة للثقافة ووجود غابة "سنط الطبيعية البرية" في وسط التنمية العمرانية لالمنطقة من أهم مميز اتها. 2. يعتبر هذا الاقليم من الأقاليم النامية الغنية بالبترول.

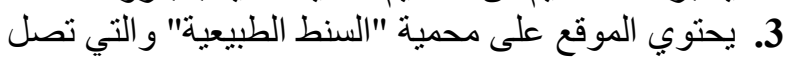

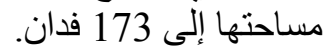

تتلخص الفكرة الأساسية للمشروع في تحويل أرض المقرن إلى إلى بانوراما فاتتة وساحرة تعكس جمال

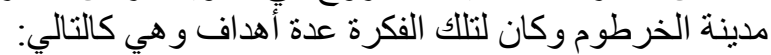

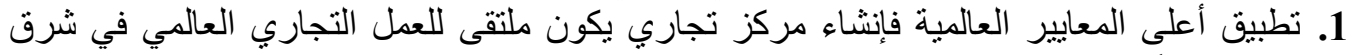

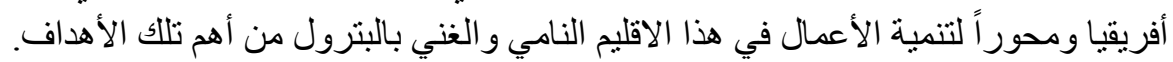

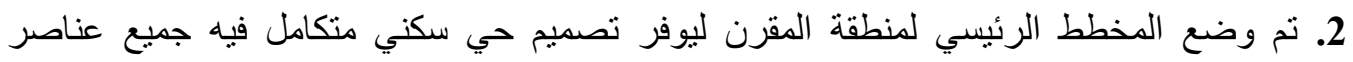

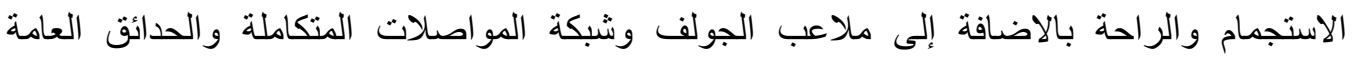

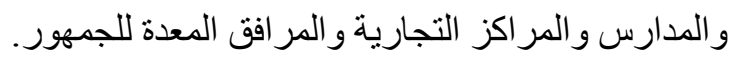

• التطوير العمراني.

التخطيط شركة دال للتنمية العقارية.

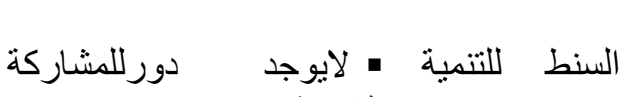
الثعبية.
• السياسات المتبعة لتطوير المنطقة:

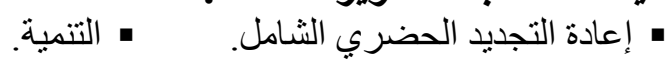

• الجهات المشاركة في تطوير المنطقة:

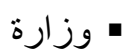
العمر اني.

• الصندوق القومي للتأمين الشركة

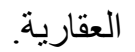

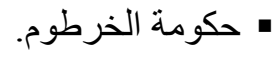

$$
\text { الاجنماعي. }
$$

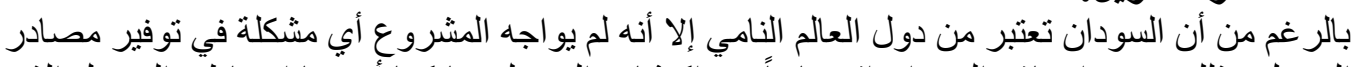

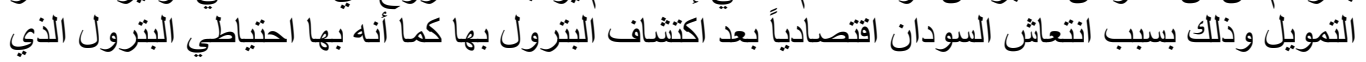

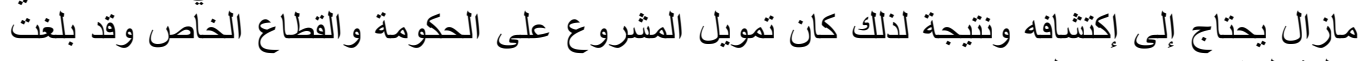
تكلفة المشروع نحو 4 مليار ات دو لار. 

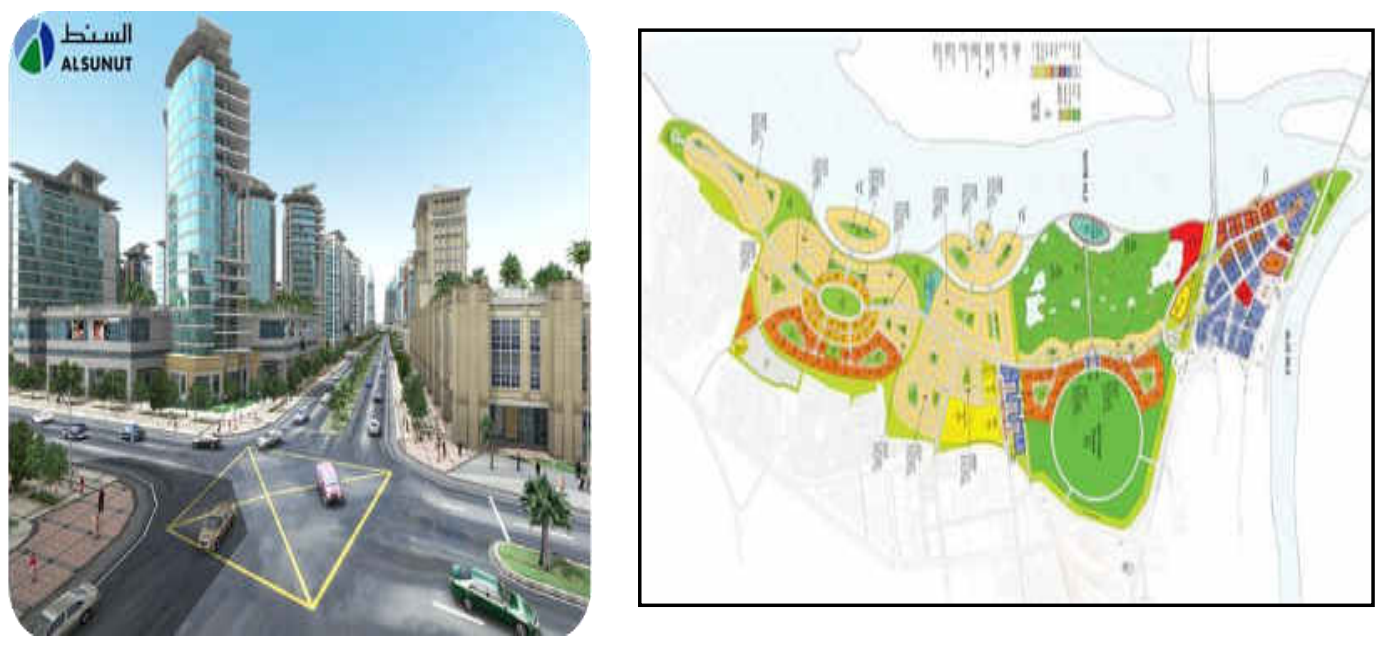

$$
\text { شكل (11): المخطط العام لأرض المقرن: Www.alsunut.com: شكل (12): الموقع العام لأرض المقرن }
$$

\section{7 .2 تطوير وإحياء النسيج العمراني لمراكز مدينة إستانبول التاريخي[16]:}

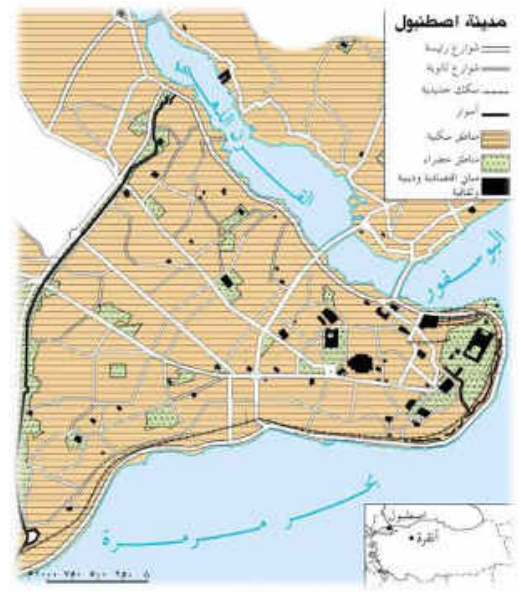

شكل (13): خريطة توضيحية للمدينة المصدر: www.arab-ency.com خريط:

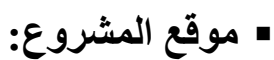

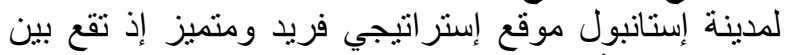

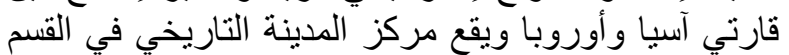

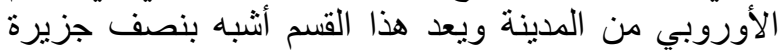

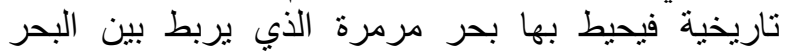

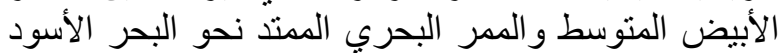

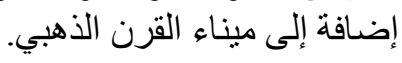

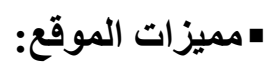

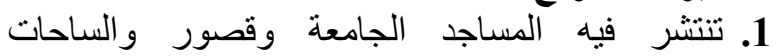
والحدائق وغيره من العناصر المعمارية الأخرى التئي تحولت إلى أماكن جذب السكان و السياح. 2. انتشر عمارة المساجد الضخمة والكان والكليات التي تحمل اسم

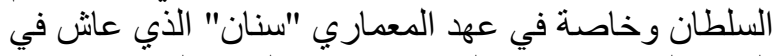

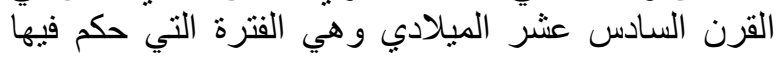

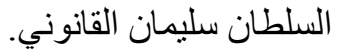

تتلخص الفكرة الأساسية للمشروع في حماية وإحياء النسيج العمر اني للمدينة و إعادة الحيوية إلى قلبها

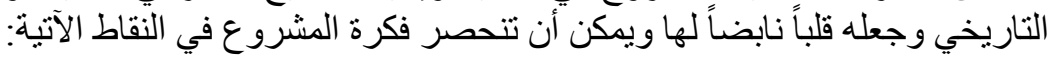

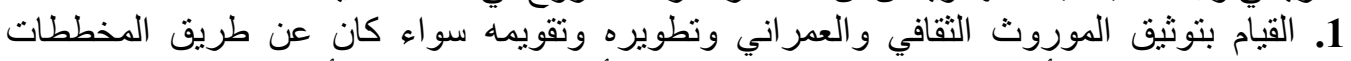

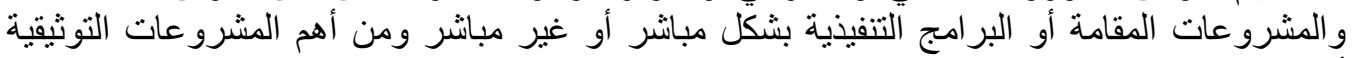

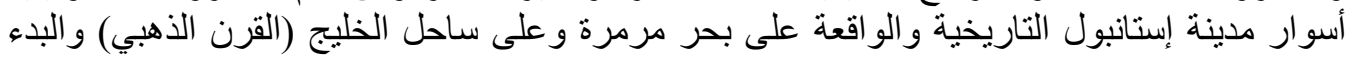




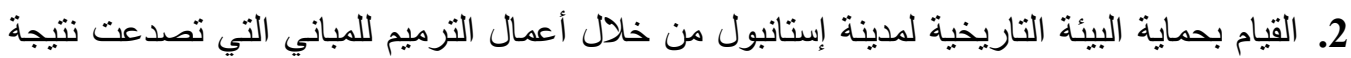

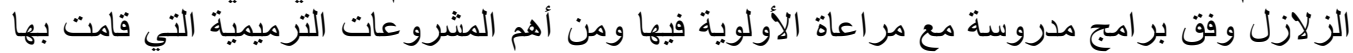

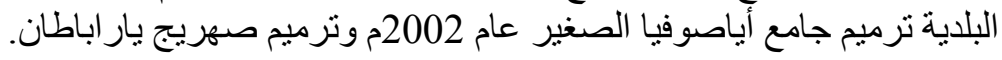

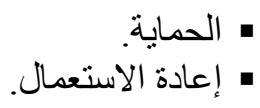

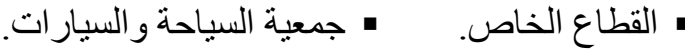

ـ السباسات المتبعة لتطوير المنطقة:

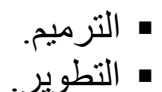

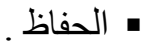

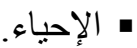
• إعادة التخطيط. إعادة التأهيل.
السلبيات الناتجة عن عملية التطوير

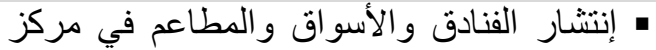

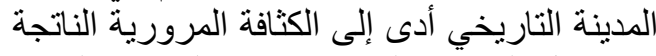
عن إقبال الزوار و السياح وسكان المدينة والتوجة النهانه

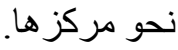

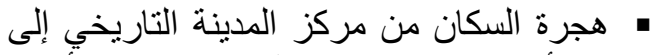
مناطق أخرى بسبب النعدام الخصوصية في الخينة ألحياء

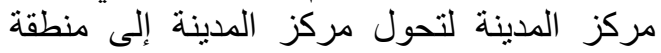

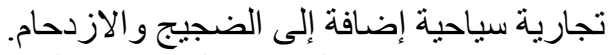

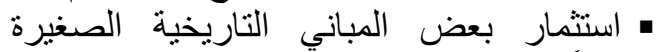

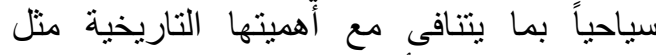

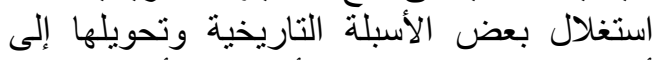

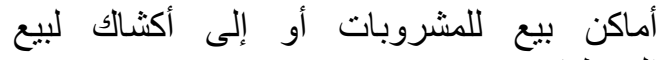

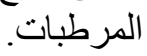

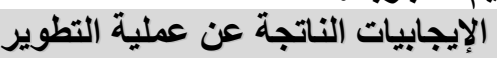

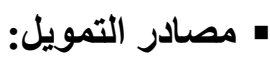
لوجود المناطق "المساجد و المو اقع التاريخية" بالمكان.

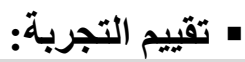

معظم مصادر تمويل المشروع كانت من قبل الحكومة حتى لايندخل القطاع الخاص في التطوير نظراً

• عدم السماح بدخول المركبات إلى مركز المدئة الندينة

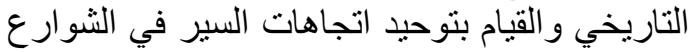
الفرعية الضيقة لتجنب الاختناقات المرورية.

• توثيق المباني التاريخية ودر اسة واجهاتها و القيام بترميم البعض الآخر بما يتماثنى مع النسيج العمر اني التاريخي لمركز المدينة.

• الاعتناء بالساحات المنتشرة في مركز مدينة إستانبول التاريخي من خلال توفير العناصر الجنات الجمالية

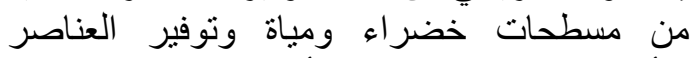
التأثيتية لتلك الساحات مثل "أماكن الجلوس، وحئ وحدات الإنارة، و اللوحات الإرشادية.
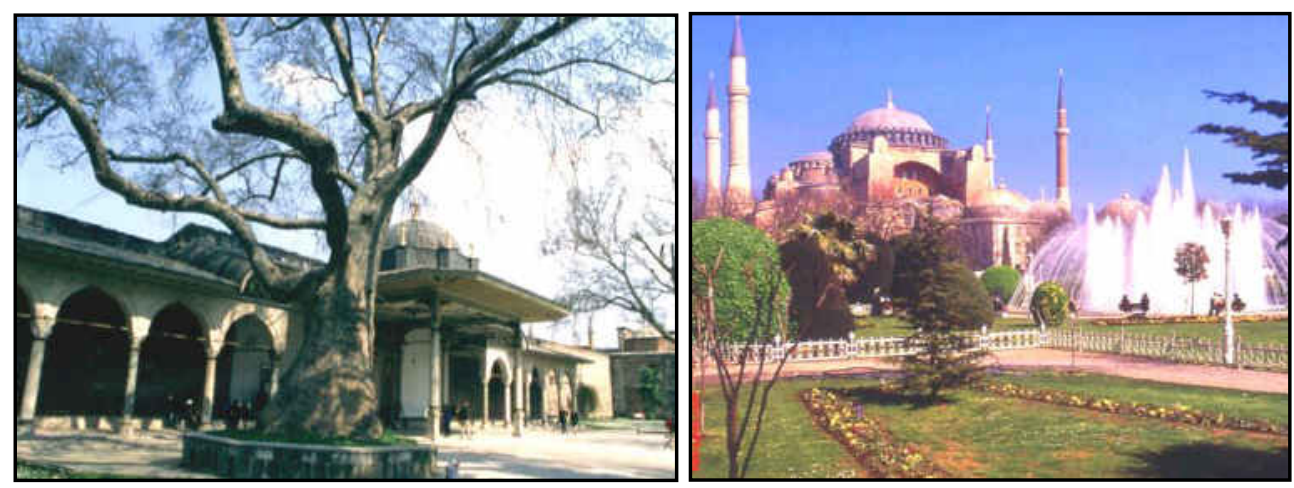

$$
\text { الفناء الخارجي لقصر طوب قابي }
$$

المصدر: www.arab-ency.com

كنيسة أياصوفيا التي تحولت إلى جامع في عهر السلطان محمد الفاتح

شكل (14): صور نوضح التنوير الحادث بالأماكن التاريخية الموجوده في مركز مدينة أسطنبول 


\subsection{2 مشروع إنشاء حديقة الأزهر بالدراسة [11]:}

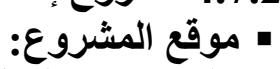

تقع الحديقة بينٍ التبلال الواقعة على شارع صلاح سلاح سالم بالقرب من القلعة وبين سور القاهرة الأيوبي

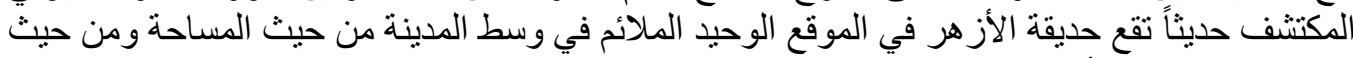

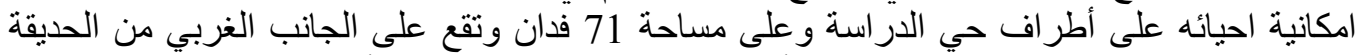

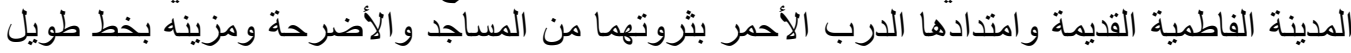

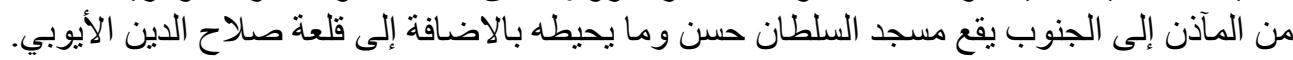

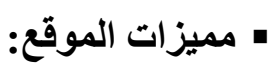
1. التلة المقام عليها الحديقة توفرمنظر مرتفع للمدينة وتعطي بانور رامي رائع للمناظر الخلابة والجذابة

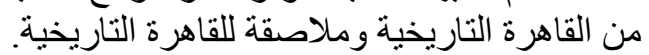
2. تعد هذه المنطقة التي تشغلها الحديقة من أغني مناطق العالم بآثار الفن و الحضارة الاسلامية.

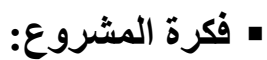
1. إقامة نماذج للتنمية قابلة للتكرار في مختلف المدن التاريخية الإسلامية علماً أن ما يقرب من ثلث الثارئ

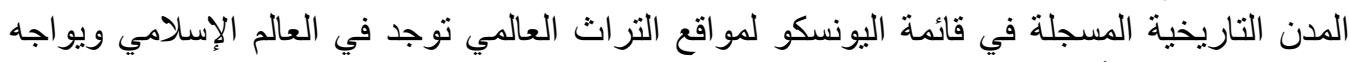

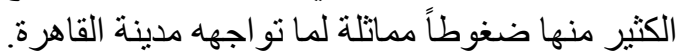
2. توفير متنفس طبيعي داخل نطاق القاهرة التاريخية المكنظة بالسكان. 3. 4. نوفير الأنشطة الترفيهية و الثقافية التي يفتقر إليها سكان المنطقة. ـ السياسات المتبعة لتطوير المنطقة:

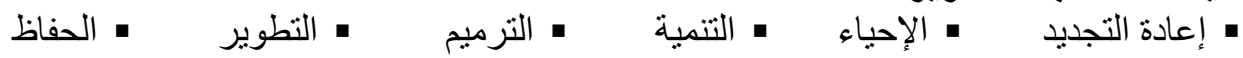

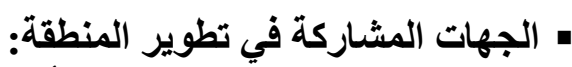

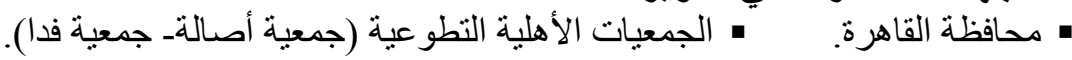

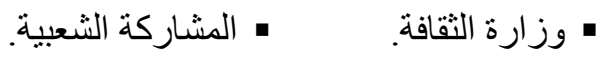
• جماعة تصميم المجتمعات بإشراف برنامجة دعم المدن التاريخية التابع لمؤسسة الاغاخان الثقافية .2000

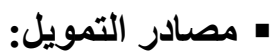

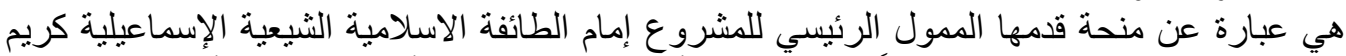

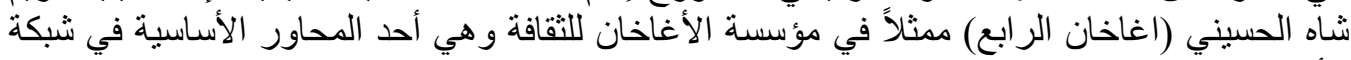

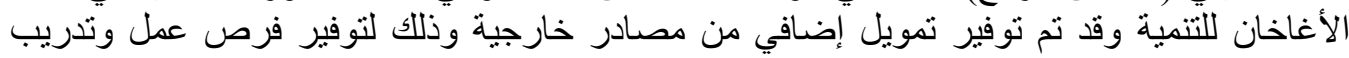

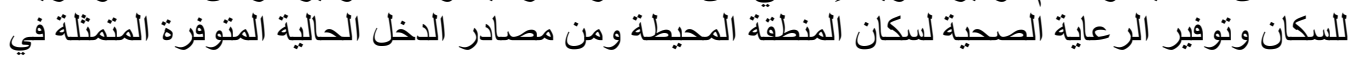
العائد من المطعم و الكافيتريا والتذاكر و هي غير المير كافية لإحتياجات الحديقة.

03 الدراسة التطبيقية: 103 مخطط الار اسة التطبيقية: 10103 10103 أهمية الدراسة التطبيقية:

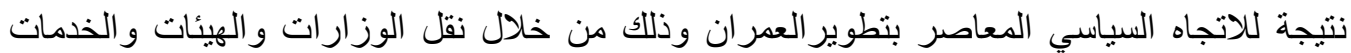

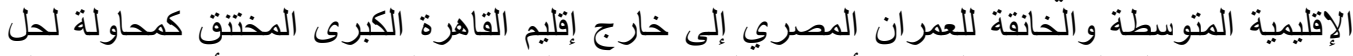

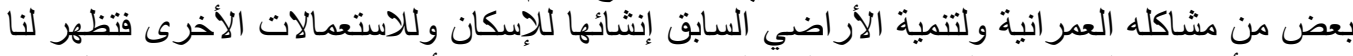
بعض الأر اضي الثاغرة والواقعة في قلب العمران وتصبح هذه الأراضي متنفس جديد وُتمثل هذه الاضن 
الأرض قيمة عمر انية و اقتصادية وتتضافر كل الجهات المعنية والمستثمرين والمستفيدين للاستيلاء عليها

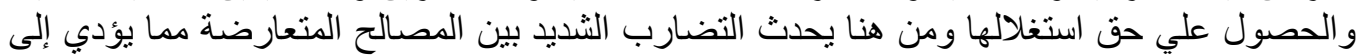

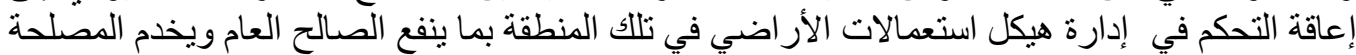

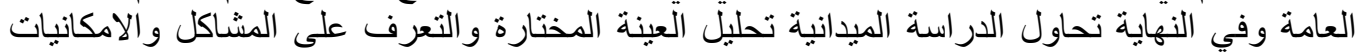

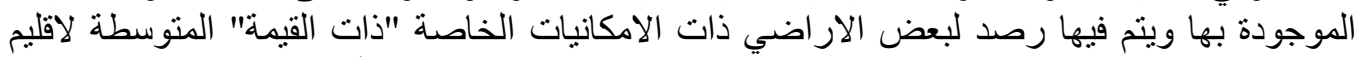

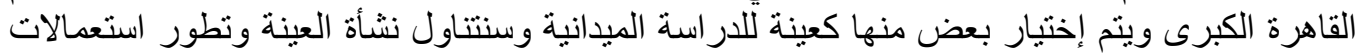

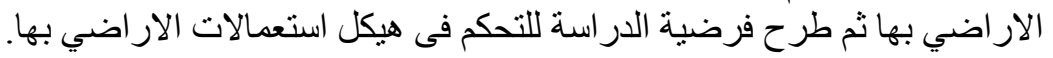

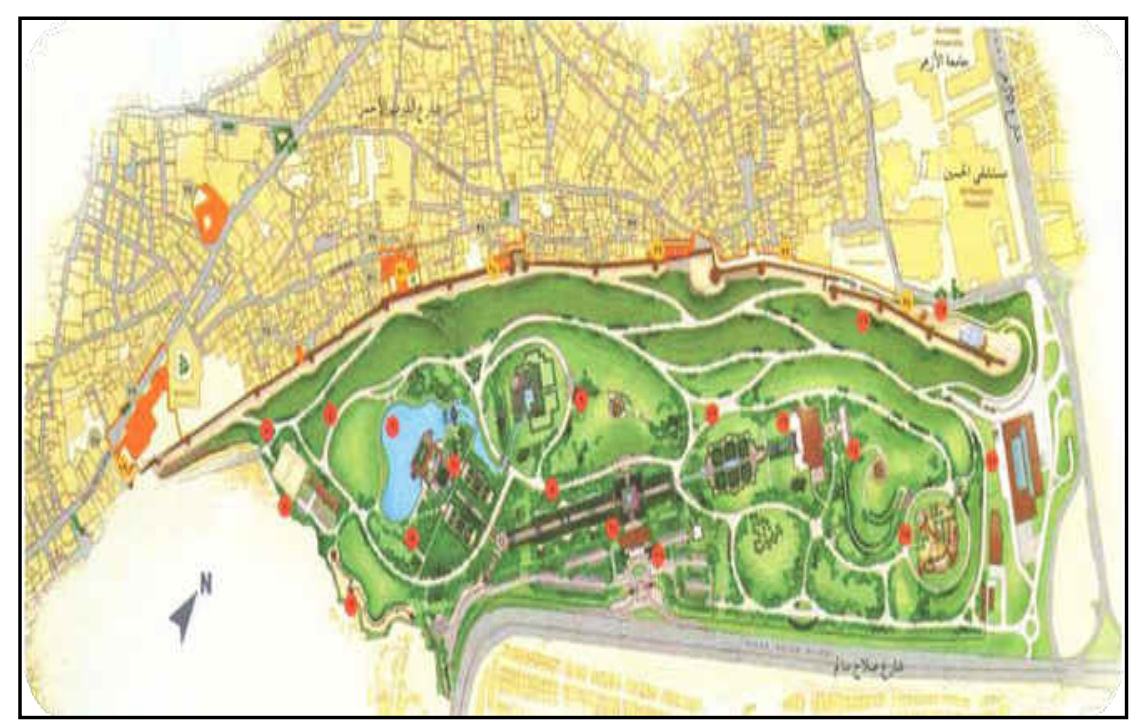

شكل (15): المخطط العام لحديقة الأزهر

المصدر: مجلة تصميم، العدد الثالث عشر العريفة مارس 2005

20103 تحديد مجال الاراسة:

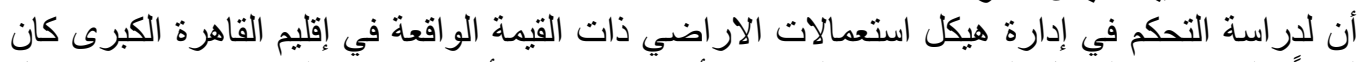

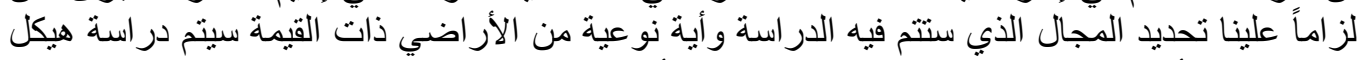

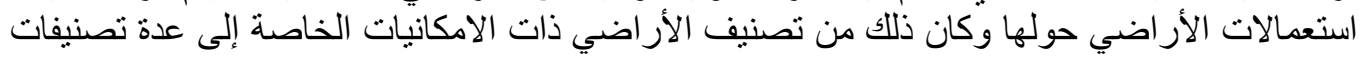
وهي:

مثل "أرض جزيرة الذهب وأرض مطار إمبابة". مثل "أر اضي الثركات و الأر اضي غيرة الذهير المستغلة". مثل "منطقة إمبابة وار اضي الثركّات الغير مستغلة".
قصيرة الأجل متوسطة طويلة الأجل طويلة الأجل ملون طيلة
إمكانيات عاجلة إمكانيات عاجلة عاجلة إمكانيات مؤجلة عاجلة 
30103 أهداف الاراسة التطبيقية:

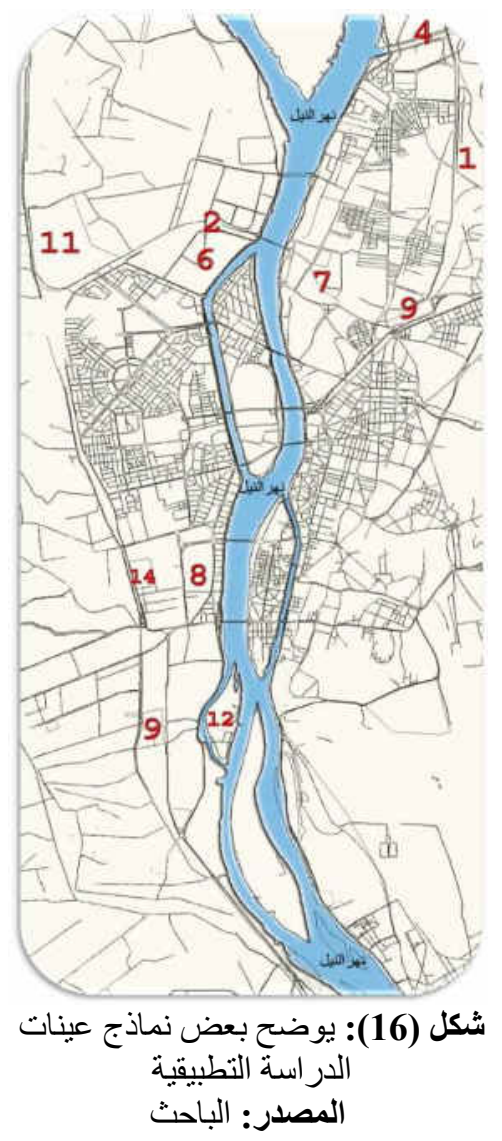

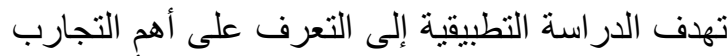

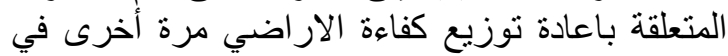

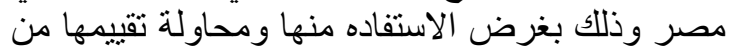

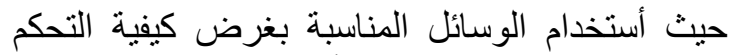

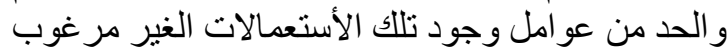

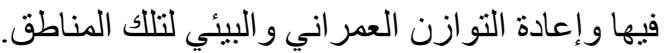

40103 تحديد نماذج الاراسة التطبيقية:

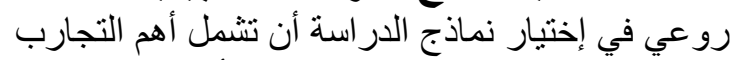

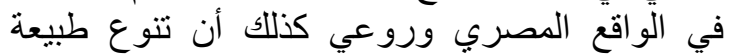
المستعملين لتلك المناطق ودرجة الخصوصية المئ المطلوبه

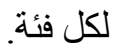

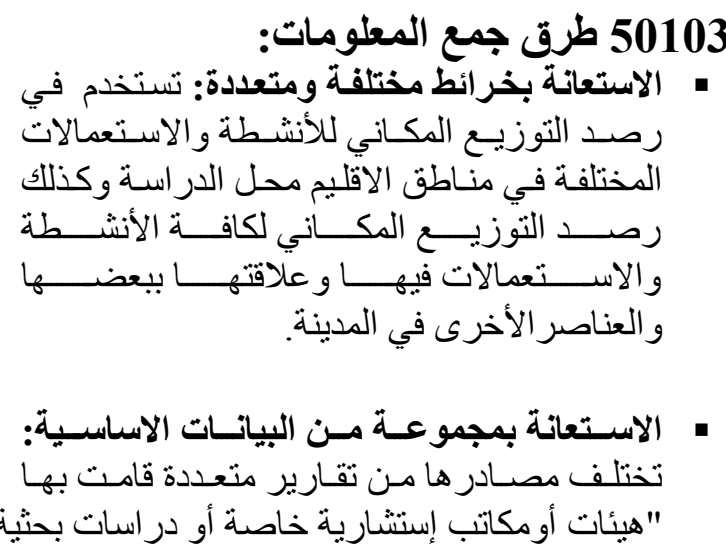

203 الدراسة التحليلية لنماذج بعض الاراضي في أقليم القاهرة الكبرى لاعادة استعمالها جدول(2): مو اقع إمكانيات مؤجلة (طويلة الأجل)

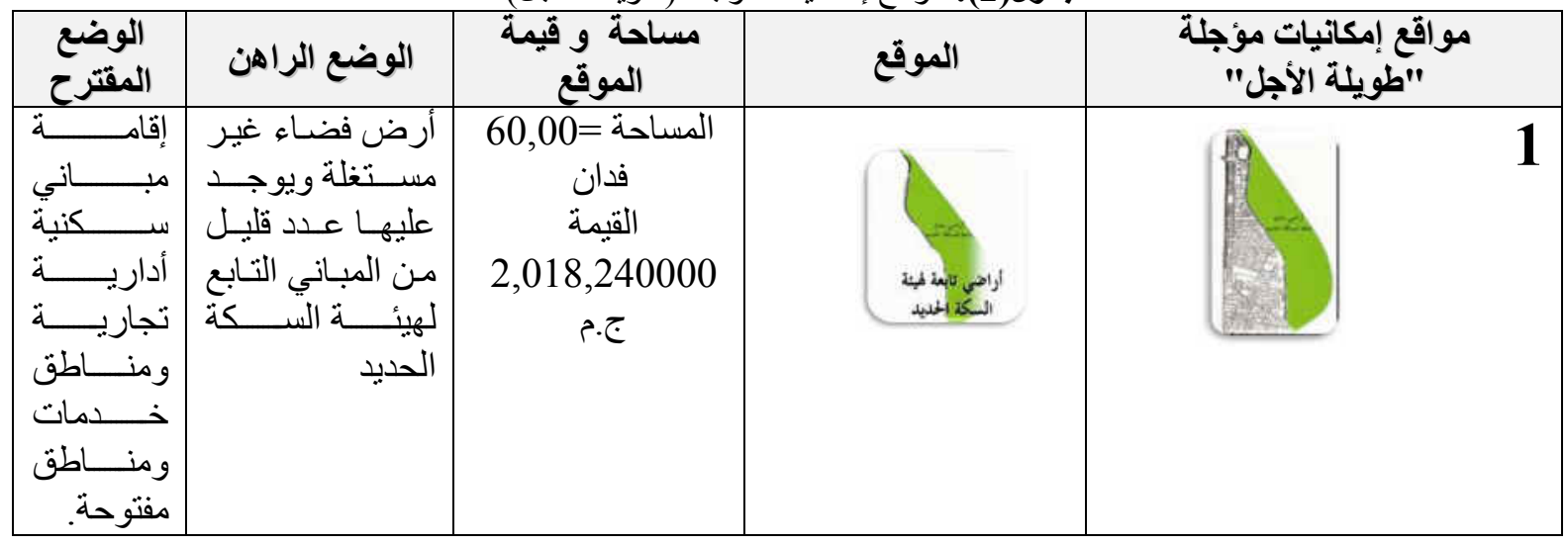




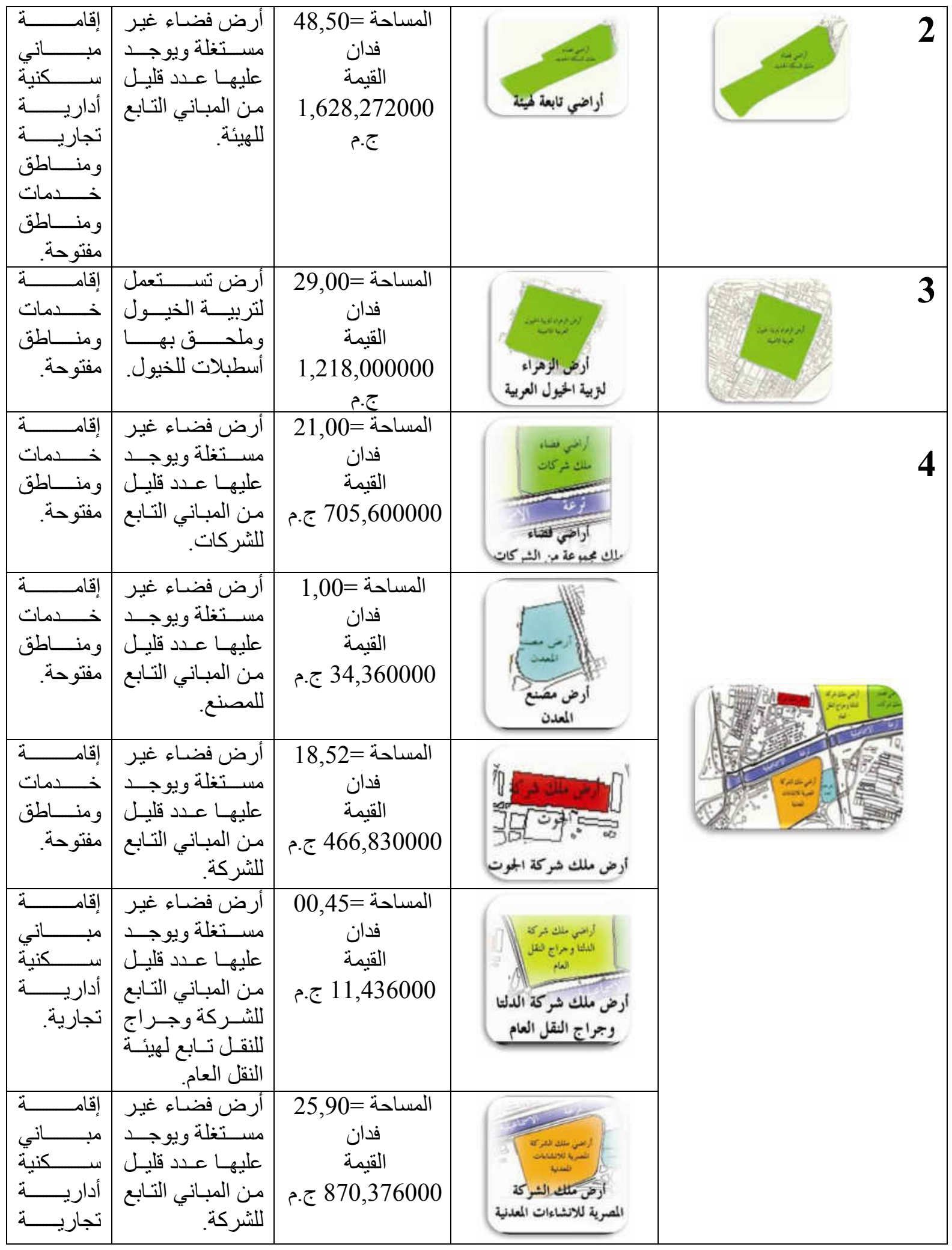




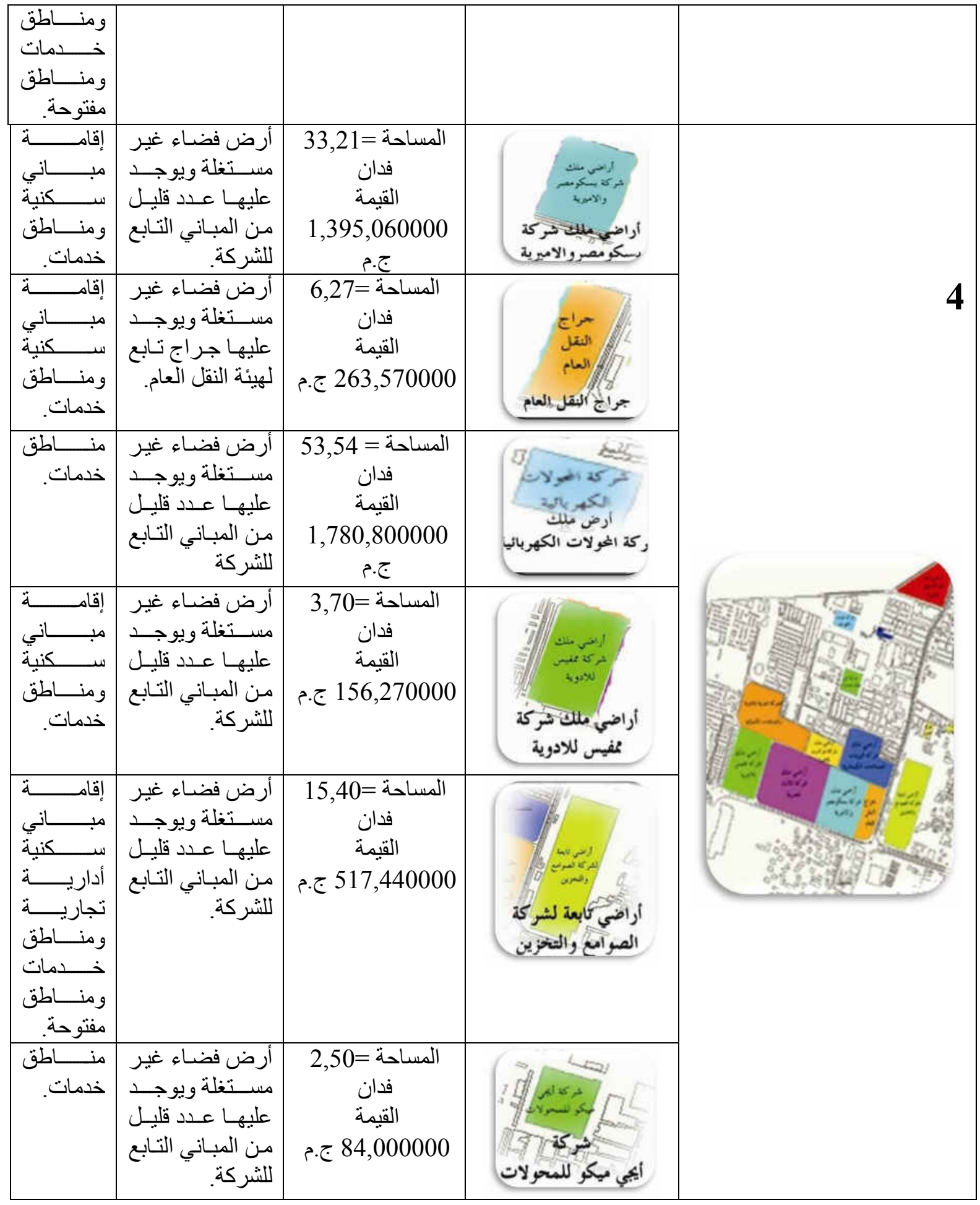




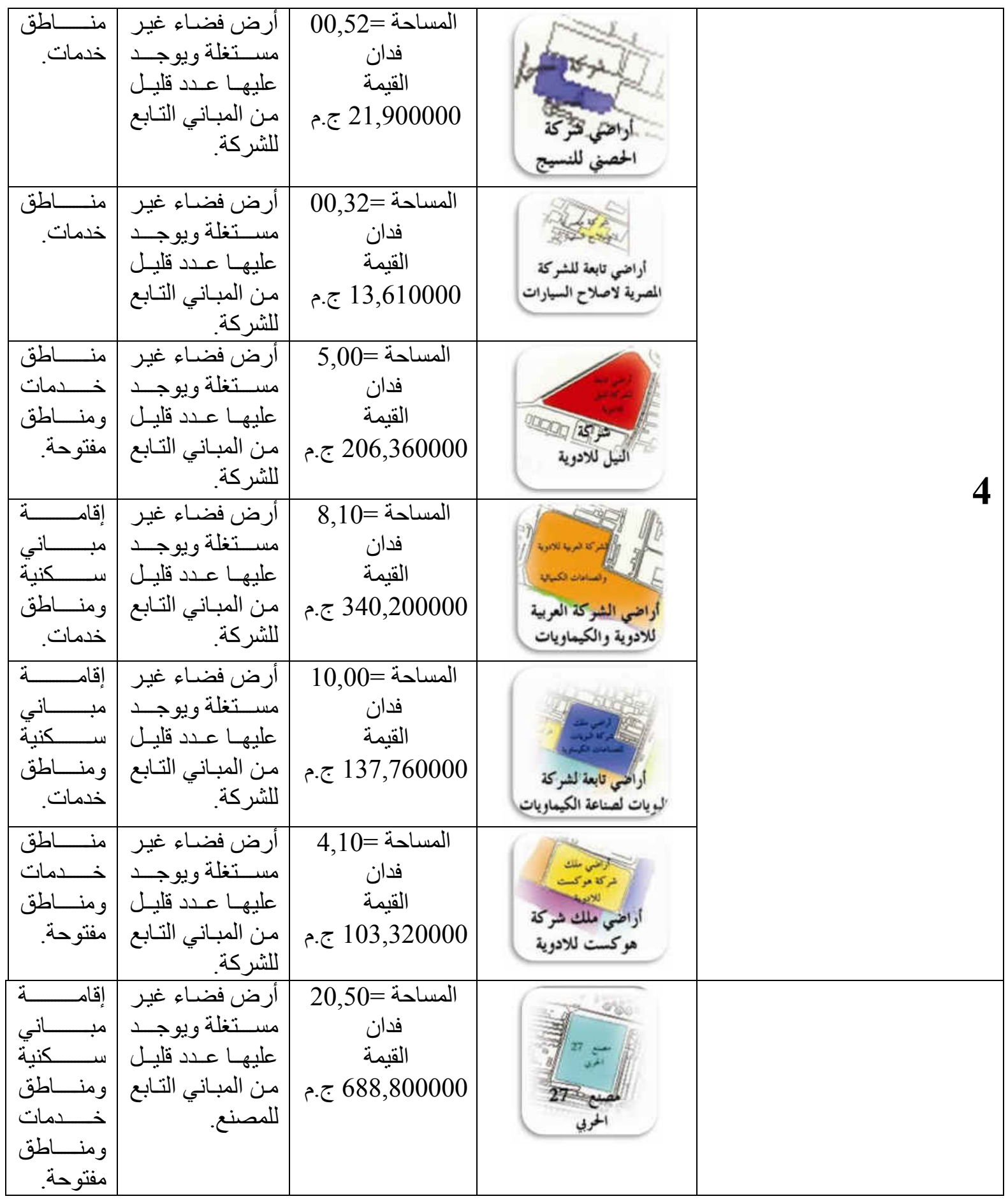




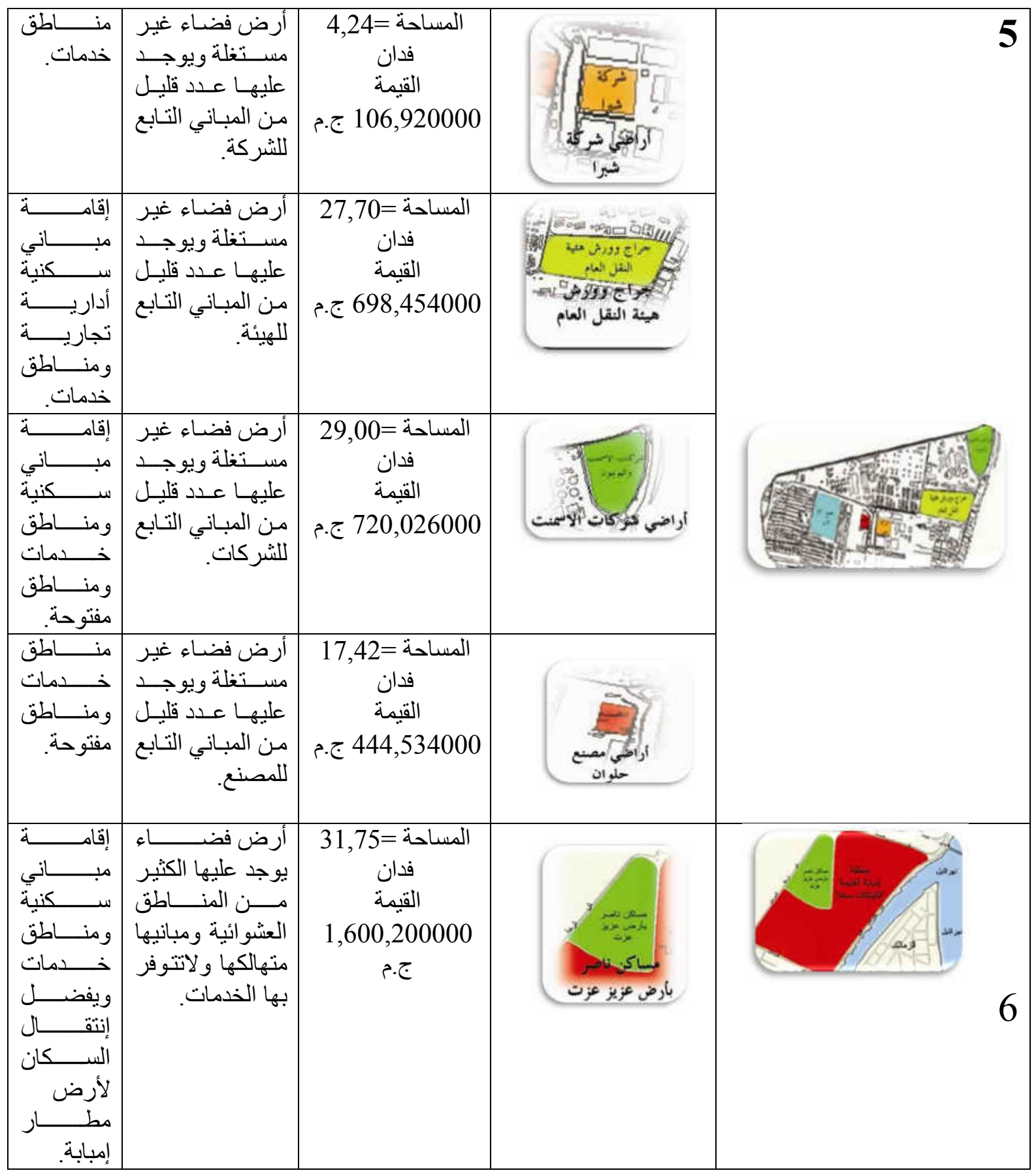




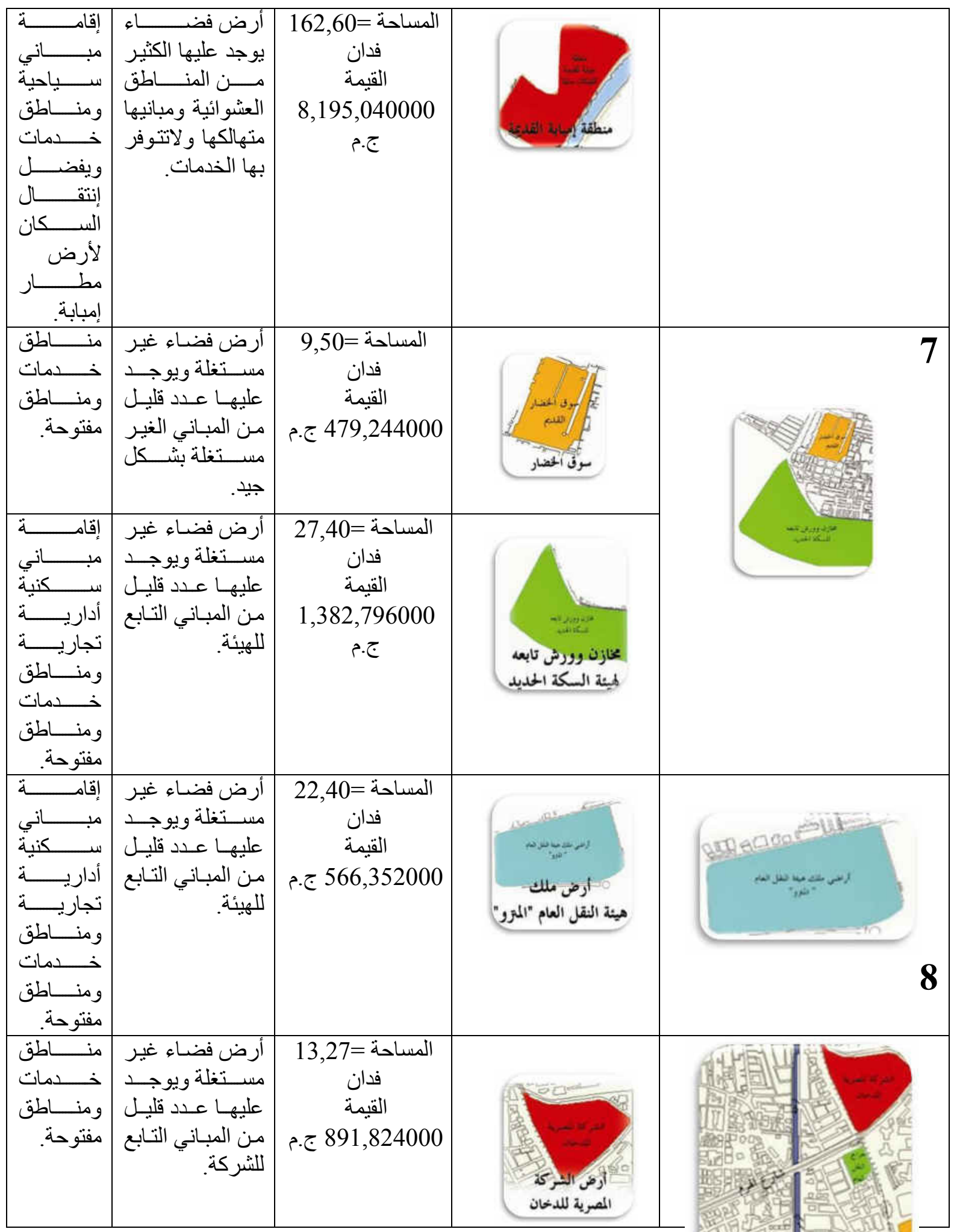




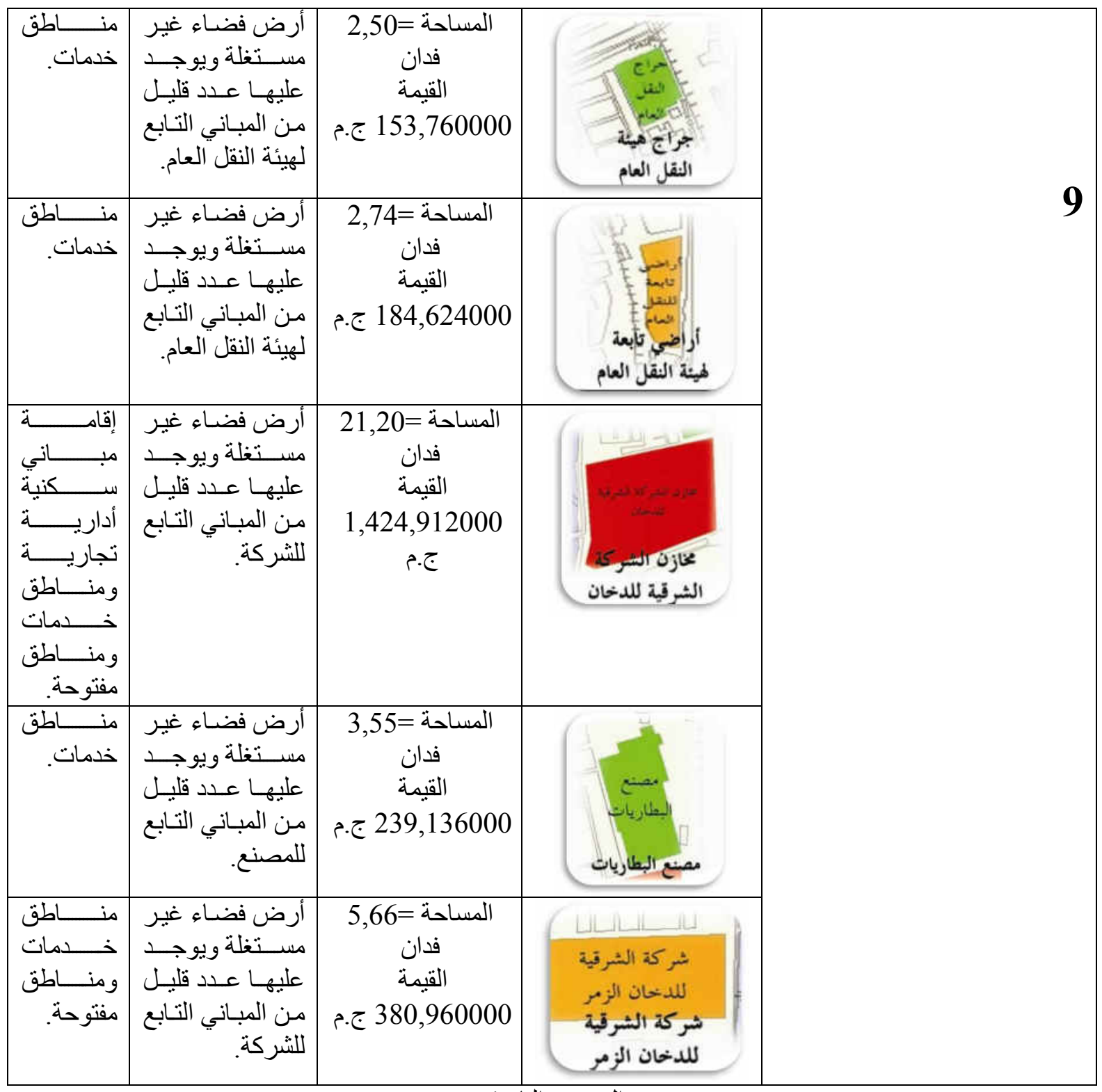

المصدر: الباحث 
جدول(3): مو اقع إمكانبات عاجلة (متوسطة طويلة الأجل)

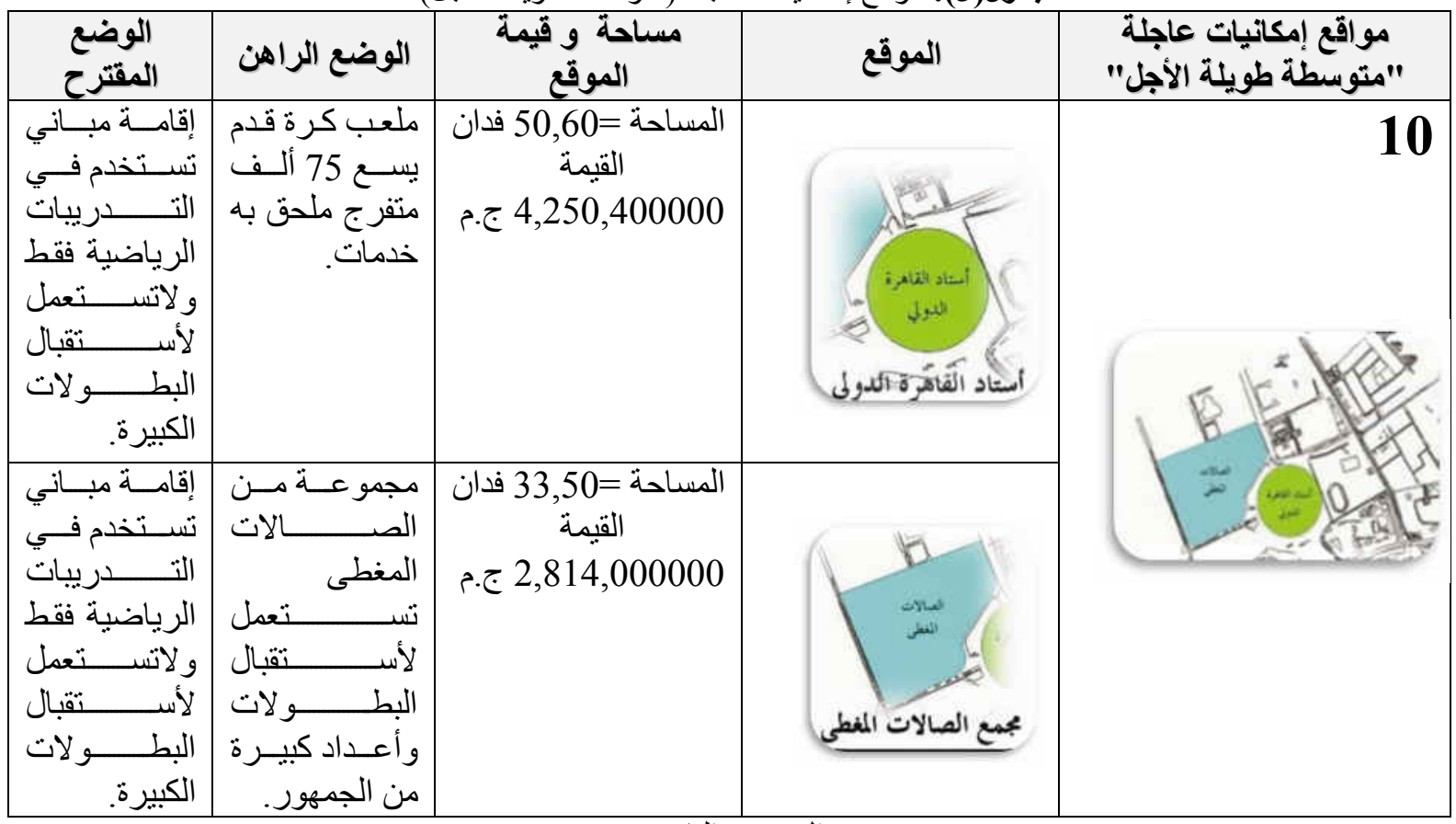

المصدر: الباحث

جدول(4): مو اقع إمكانيات عاجلة (قصبرة الأجل)

\begin{tabular}{|c|c|c|c|c|}
\hline الوضع المقترح & الوضع الراهن & مساحة و قيمة الموقع & الموقع & مواقع إمكانيات عاجلة الأجل" \\
\hline 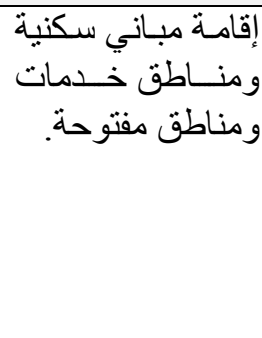 & 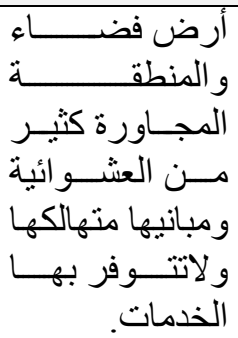 & 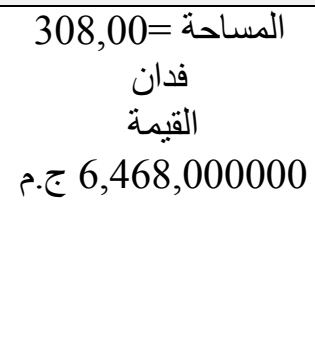 & & \\
\hline 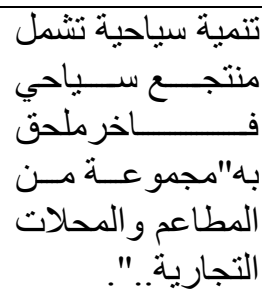 & 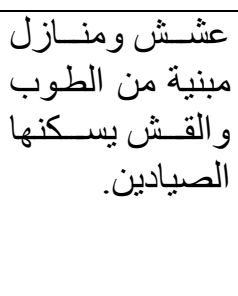 & المساحة = القيمة 70,00 فدان & & \\
\hline
\end{tabular}




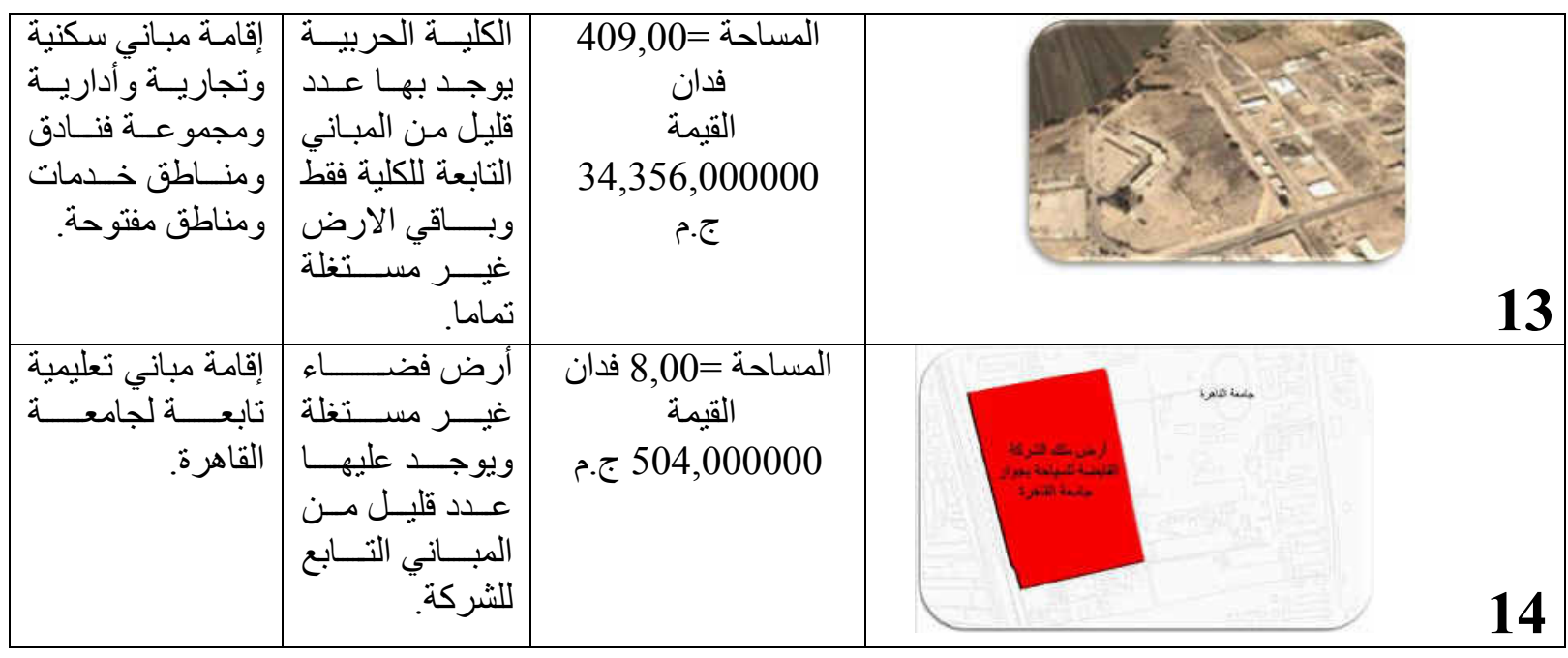

\section{المصدر: الباحث}

جدول(5): تقييم الدر اسة التطبيقية

\begin{tabular}{|c|c|c|}
\hline \multicolumn{2}{|c|}{ مواقع إمكانيات عاجلة "قصيرة الأجل" } & بيانات \\
\hline \multicolumn{2}{|c|}{4} & عدد الأراضي الكلية \\
\hline \multicolumn{2}{|c|}{ 795,00 فدان 795, } & مساحة الأراضي الكلية (فدان) \\
\hline \multicolumn{2}{|c|}{ 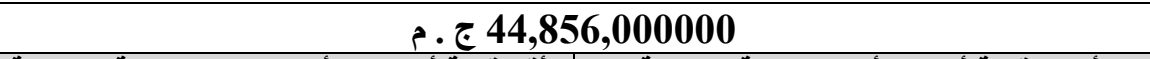 } & قيمة الأراضي الكلية ج.م \\
\hline 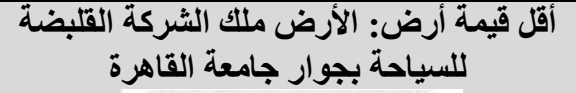 & أعلى قيمة أرض: أرض الكلية الحربية & بيانات \\
\hline 8,00 فدان & 409,00 فذان & مساحة الأرض الكلية (فدان) \\
\hline 2504,000000 & 34,356,000000 ج.م & قيمة الأرض الكلية ج.م. \\
\hline وياقي الارضا عدد قليل مستفلة تمبامي التابعة للشركة & 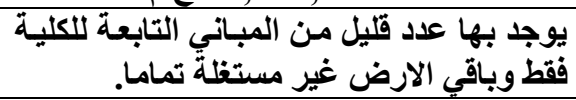 & الوضع الراهن \\
\hline إقّامةً مباني تعليميةٌة تابعة لجامعة القاهرة. & 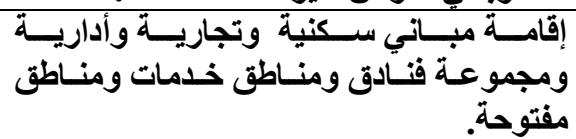 & 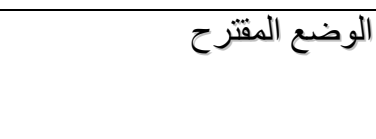 \\
\hline \multicolumn{2}{|c|}{ مواقع إمكاتيات عاجلة "متوسطة طويلة الأجل" } & بيانات \\
\hline \multicolumn{2}{|c|}{2} & عدد الأراضي الكلية \\
\hline \multicolumn{2}{|c|}{ 84,10 فدان } & مساحة الأر اضي الكلية (فدان) \\
\hline \multicolumn{2}{|c|}{ 17,064,400000 ج . م } & قيمة الأراضي الكلية ج.م \\
\hline
\end{tabular}


أقل قيمة أرض: مجمع الصالات المغطى

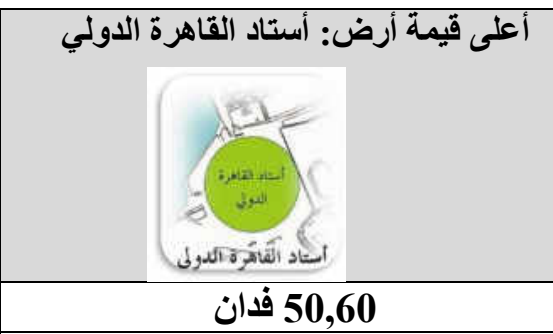

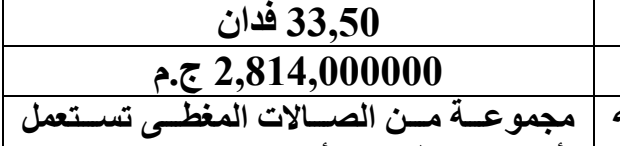

\subsection{0,400000}

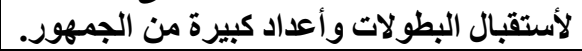

ملعب كرة قدم يسع 75 ألف متفرج ملحق بـ

إقامة مباني تستخدم في التذريبات الرياضية فقط ولاتستعمل لأستقبال البطولات الكبات الكبيرة.

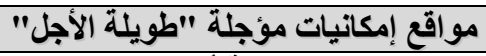

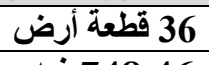

748,46

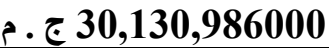

أقل قيمة أرض: أرض ملك شركة الدالتا

وجراج النقل العام شرئ

أعلى قيمة أرض: منطقة إمبابة أمام جزيرة

مساحة الأرض الكلية (فدان)

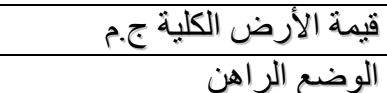

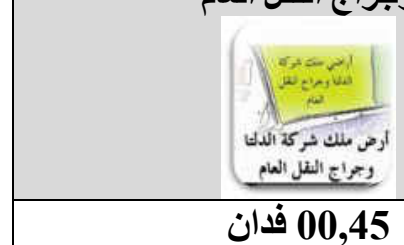

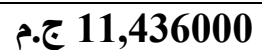

أرض فضساء غير مستغلة ويوجد عليها عليها عدلد

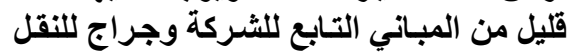
تابع لهيئة النقل العام. إقامة مباني سكنية أدارية تجارية. الزمالك إن باب

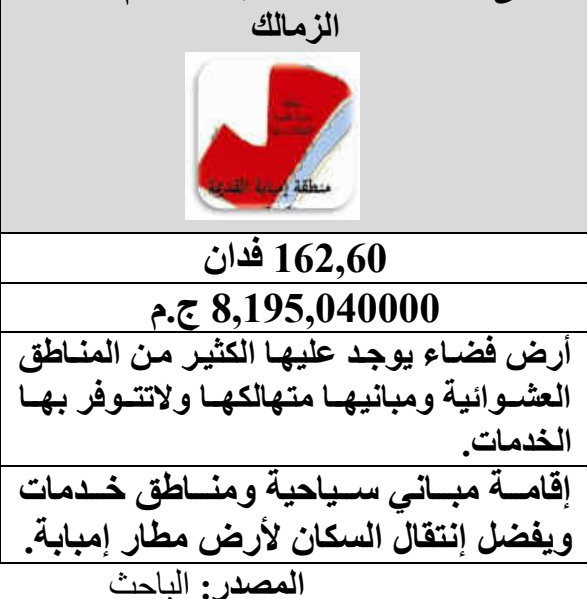

\section{04}

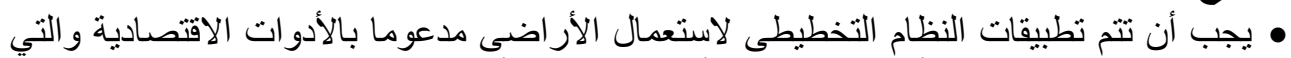

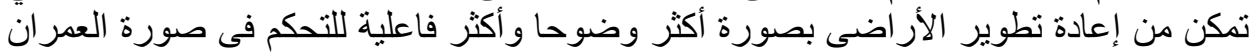

• أن إقامة عمليات واضحة تحت شعار التخطيط و المر اقبة والإدارة لتحديد احتباجات الإسكان

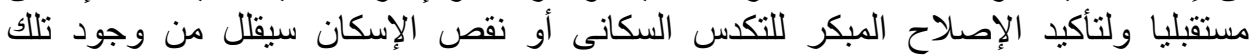
• لابد من إنماء كل السلطات المحلية للتخطيط بالقيام بدراسة الإمكانيات الحضارية بانظظام كجزء

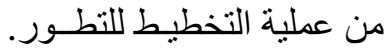

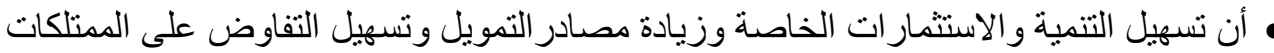

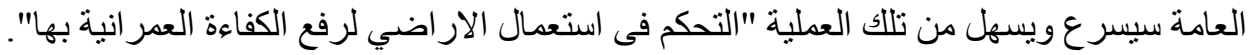

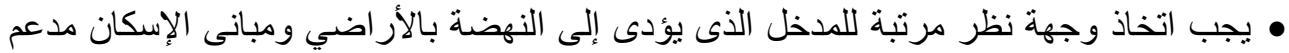
بنظام محلى لتسوية احتياجات ومتطلبات الإسكان. 
• أن خطط إدارة العمر ان "إدارة الار اضي ذات القيمة" لايمكن معالجتها أو إدارتها بنفس الطريقة

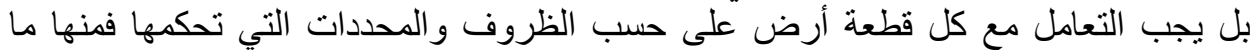

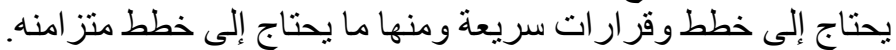

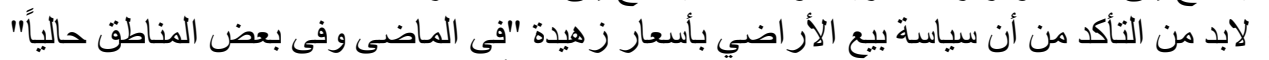

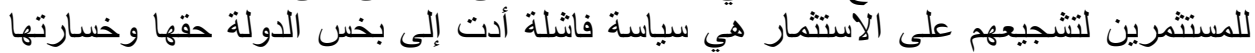

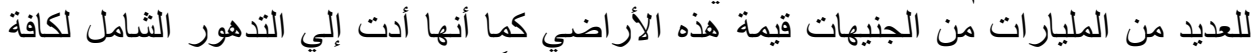

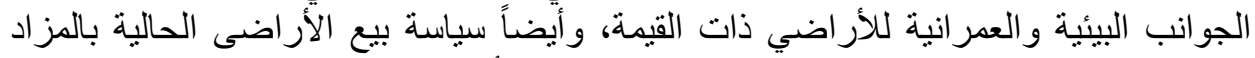

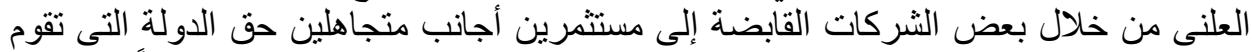

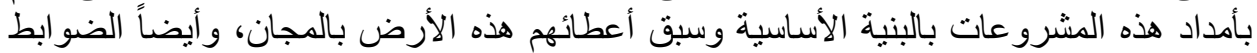

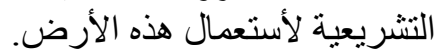

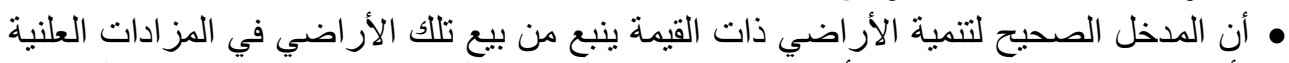

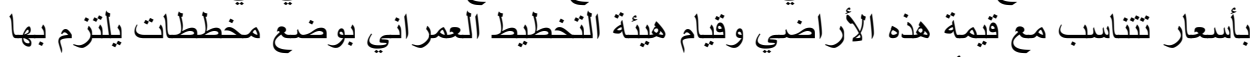

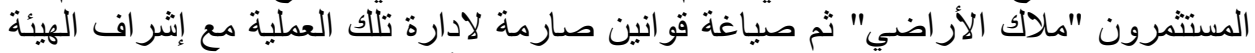

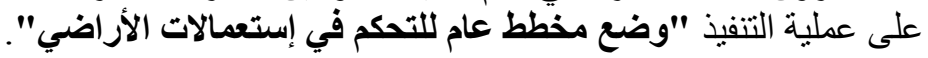

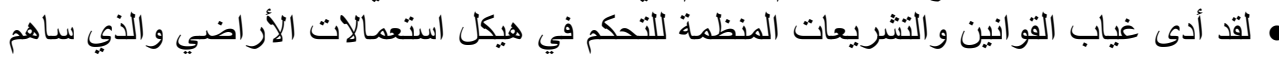

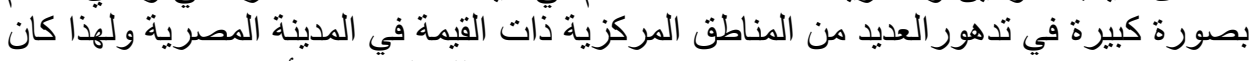

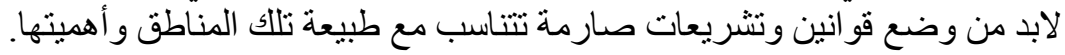

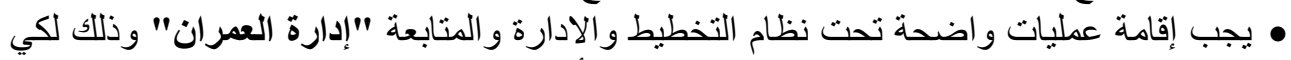

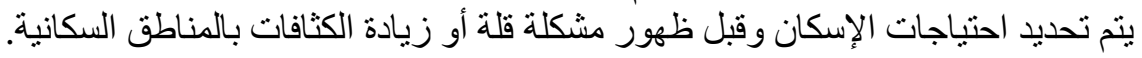

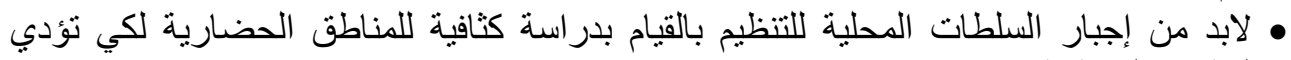
لتنطوير التخطيط بها. • أن إيجاد أهداف طموحة بالنسبة للإسكان الحديث قد تؤدي للنطوير والزيادة فى المناطق

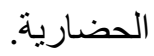
• لابد من المحافظة على النسبة بين التطور السكنى والحزام الأخضر حول الددينة ليكون متنفسا • يجب تقديم المعلومات عن قدرة الصلاحية للأر اضي و المباني مستقبلياً.

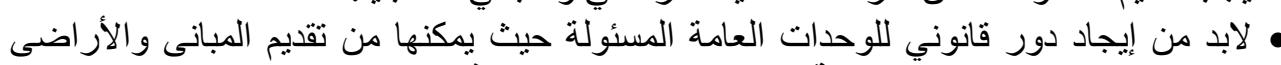

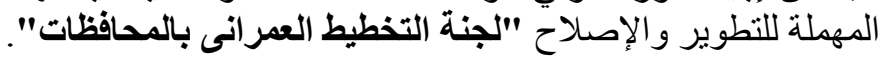

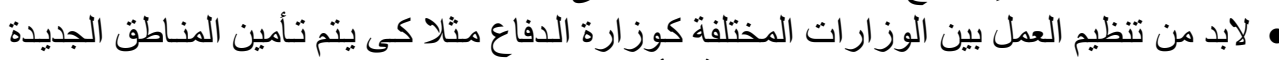

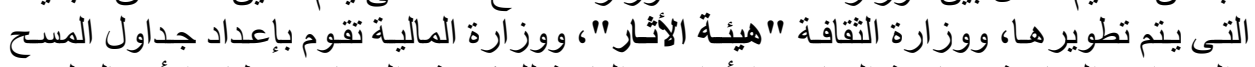

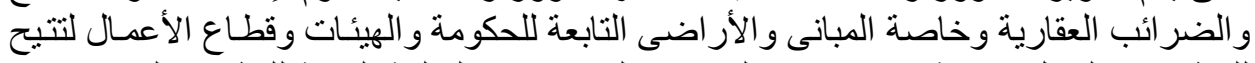

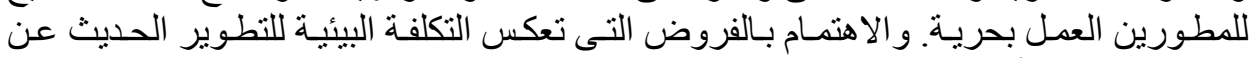

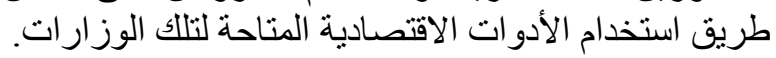

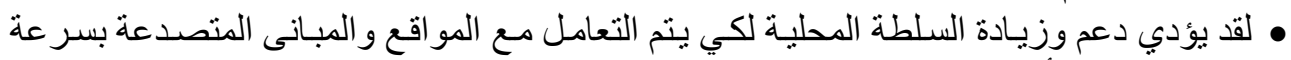

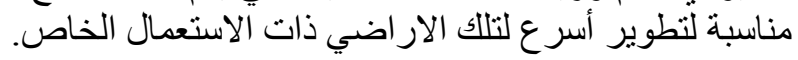

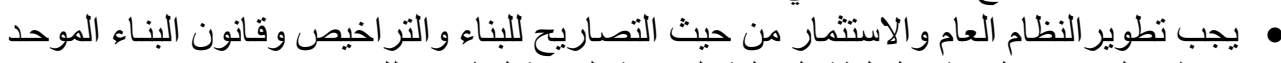
و إعطاء الوحدات العامة و السلطة المحلية المرونة المادية المادية لتطبيق ذلكاء للك.

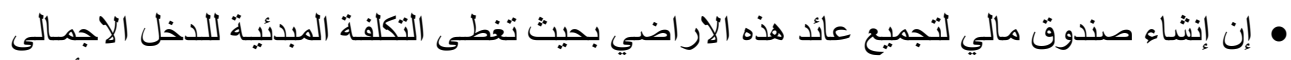

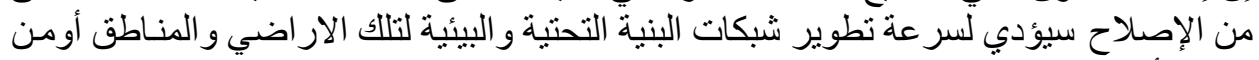

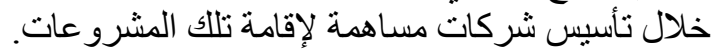

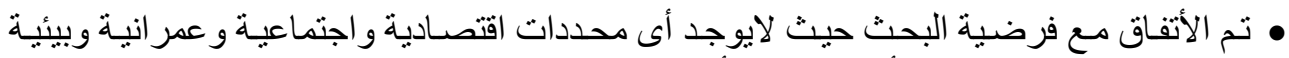

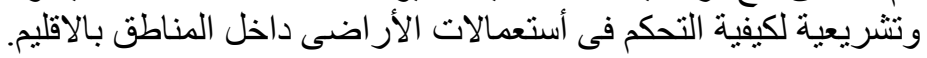




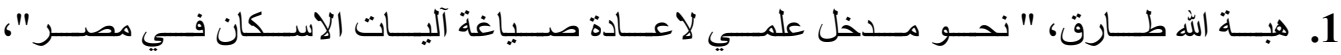

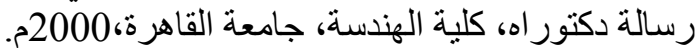

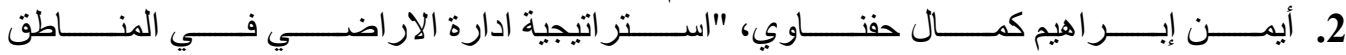

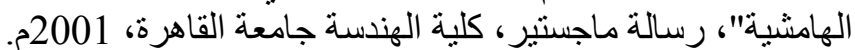

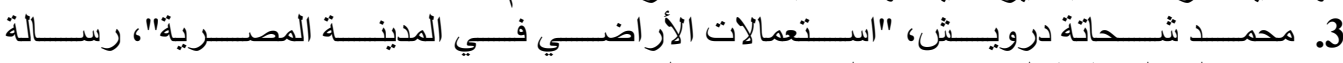

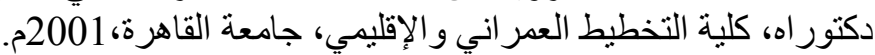

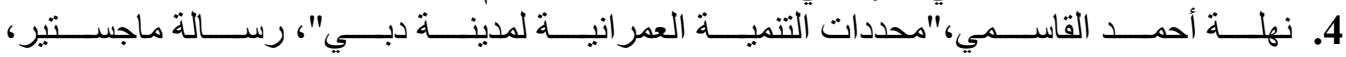

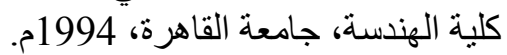

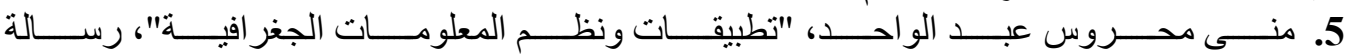
ماجستير ، كلية الهندسة، جامعة القاهرة 2004 م. 200 م.

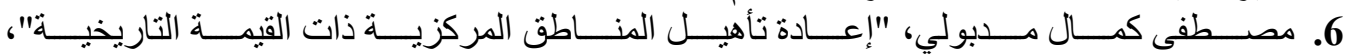

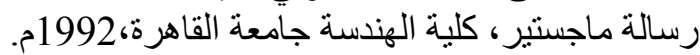

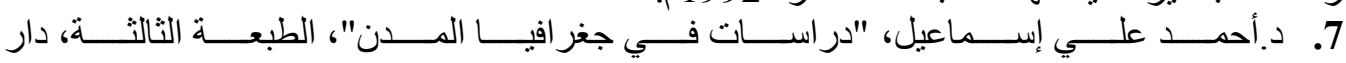
الثقافة للنشر ، القاهرة 1985م.

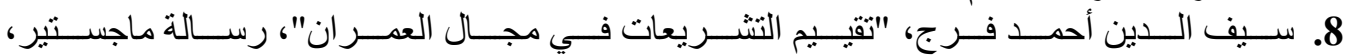
كلية الهندسة، جامعة القاهرة 1992م.

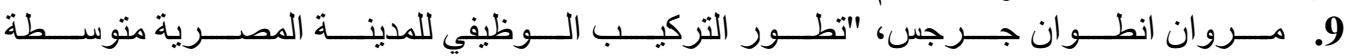

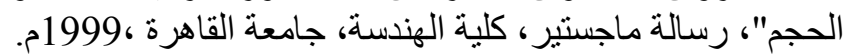

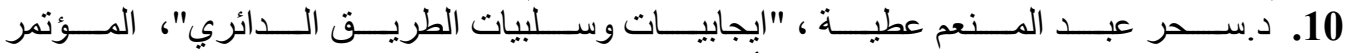

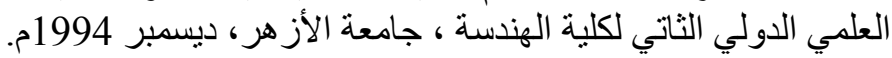

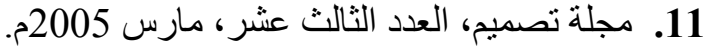

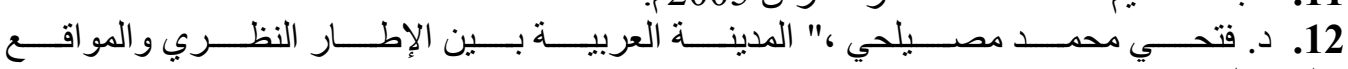

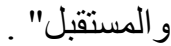

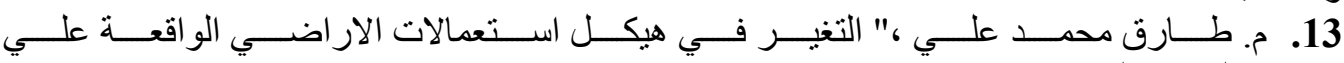
شر ايين الحركة الرئيسية". 2.5

14. www.lilwatan.com/theconstruction.htm

15. www.alsunut.com

16. www.arab-ency.com

3.5

- Beaton, W. Patrick, 1991: The Impact of Regional Land-Use Controls on Property Values: The Case of the New Jersey Pinelands. Land Economics, May 1991 Vol. 67 No. 2, pp. 172-94

- Richardson, Harry W. 1998: Regional and Urban Economics.

- Massa, Bryan H. 1986: Spatial Search, Applications to Planning Problems in the Public Sector. Canada.

- Antony, J. Cantonese \& James C. Snyder 1979: Introduction to Urban Planning, McGraw - Hill book.

- Steiner, Frederick \& Kent butler. 2007: Planning and Urban Design Standards, American Planning Association. 